Article

\title{
Comparative Study of Microstructure and Mechanical Properties of Two TiAl-Based Alloys Reinforced with Carbide Particles
}

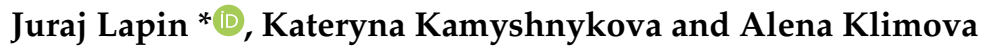 \\ Institute of Materials and Machine Mechanics, Slovak Academy of Sciences, Dúbravská cesta 9, \\ 84513 Bratislava, Slovak Republic; kateryna.kamyshnykova@savba.sk (K.K.); alena.klimova@savba.sk (A.K.) \\ * Correspondence: juraj.lapin@savba.sk; Tel.: +421-2-3240-1059
}

Academic Editor: Derek J. McPhee

Received: 9 July 2020; Accepted: 24 July 2020; Published: 28 July 2020

check for

updates

\begin{abstract}
Microstructure and mechanical properties of two TiAl-based alloys with nominal composition Ti-42.6Al-8.7Nb-0.3Ta-2.0C and Ti-41.0Al-8.7Nb-0.3Ta-3.6C (in at.\%) were investigated and compared. The alloys were prepared by vacuum induction melting, followed by centrifugal casting. The as-cast samples were subjected to hot isostatic pressing and heat treatment consisting of solution annealing in $\beta$ (Ti-based solid solution) phase field, cooling at a constant rate and stabilization annealing. The microstructure of the alloys consists of $\alpha_{2}\left(\mathrm{Ti}_{3} \mathrm{Al}\right)+\gamma(\mathrm{TiAl})$ lamellar grains, single $\gamma$ phase, coarse $\mathrm{Ti}_{2} \mathrm{AlC}$ particles, and irregular shaped $\alpha_{2}$ phase. The increase in the content of $\mathrm{C}$ at the expense of decreasing $\mathrm{Al}$ in the studied alloys affects solid-state phase transformation temperatures and leads to a decrease in size of grains and primary $\mathrm{Ti}_{2} \mathrm{AlC}$ particles, increase in the volume fraction of reinforcing carbide particles, decrease in the volume fraction of lamellar colonies, and widening of the grain boundaries. Long-term ageing at $800{ }^{\circ} \mathrm{C}$ has no effect on the grain size but leads to the formation of $\mathrm{Ti}_{4} \mathrm{Al}_{3} \mathrm{Nb}$ particles and increase in interlamellar spacing. The Vickers hardness, microhardness of lamellar grains, indentation nanohardness, and elastic modulus of the boundary $\gamma$ phase decrease during ageing. The Ti-42.6Al-8.7Nb-0.3Ta-2.0 C alloy shows improved creep resistance compared to that of Ti-41.0Al-8.7Nb-0.3Ta-3.6C and some reference TiAl-based alloys at a temperature of $800{ }^{\circ} \mathrm{C}$ and applied stress of $200 \mathrm{MPa}$.
\end{abstract}

Keywords: intermetallics; TiAl; carbides; heat treatment; microstructure; hardness; creep

\section{Introduction}

Lightweight intermetallic alloys based on ternary TiAl-Nb system are of great interest for applications in the aerospace, power engineering, and automotive industries due to their high specific strength, high melting temperature, good high temperature creep strength, and oxidation resistance [1,2]. The increasing demand for higher efficiency of aircraft engines and higher operating temperatures of turbocharger wheels enforce the development of more creep-resistant lightweight alloys. Depending on chemical composition and applied processing techniques, TiAl-based alloys can be produced with different types of microstructure such as fully lamellar, nearly lamellar, duplex, and near gamma [3-5]. The duplex and near gamma alloys are characterized by higher room temperature ductility, tensile strength, and longer fatigue life than fully or nearly lamellar ones [6]. Better creep resistance of fully or nearly lamellar TiAl-based alloys has been related to highly anisotropic lath structure and reduction in interlamellar spacing $[7,8]$.

It is well known that substitutional elements like $\mathrm{Nb}, \mathrm{Mo}, \mathrm{Ta}$, and $\mathrm{W}$ as well as the interstitial elements such as $\mathrm{C}$ improve high temperature creep resistance of TiAl-based alloys [9-13]. The addition of carbon up to about 0.8 at.\% contributes to precipitation strengthening through the formation of 
two types of fine carbides: cubic perovskite-type $\mathrm{Ti}_{3} \mathrm{AlC}$ (P-type) with needle-like morphology and hexagonal $\mathrm{Ti}_{2} \mathrm{AlC}$ (H-type) with plate-like morphology [12,14-16]. Higher content of carbon (above 1 at.\%) leads to the formation of coarse primary H-type carbide particles during solidification [17-21]. The $\mathrm{H}-\mathrm{Ti}_{2} \mathrm{AlC}$ is a thermodynamically stable phase with a unique combination of both metallic and ceramic properties such as high fracture resistance, excellent damage tolerance, good thermal and electrical conductivity, easy machinability, good thermal shock and oxidation resistance, high elastic modulus, and thermomechanical stability [22]. Furthermore, the density and thermal expansion coefficient of $\mathrm{Ti}_{2} \mathrm{AlC}$ are close to those of TiAl-based alloys, which largely avoid the phenomena of segregation of the carbide particles and reduce inner stresses between the reinforcement and the matrix during fabrication. The contribution of carbides to the strengthening of TiAl-based alloys strongly depends on their size and distribution in the intermetallic matrix [23-25]. Coarse uniformly distributed primary $\mathrm{Ti}_{2} \mathrm{AlC}$ particles increase toughness by bridging and blunting of propagating cracks $[19,26]$. Fine secondary $\mathrm{P}-\mathrm{Ti}_{3} \mathrm{AlC}$ and $\mathrm{H}-\mathrm{Ti}_{2} \mathrm{AlC}$ precipitates improve high temperature creep resistance by hindering dislocation motion and grain boundary sliding [27-29]. Despite previous studies on the design and properties of TiAl-based alloys reinforced with carbon particles, very limited information has been published about the effect of substitution of $\mathrm{C}$ for $\mathrm{Al}$ in a system with fully lamellar structure on solid-state phase transformations, microstructure, distribution of primary carbide particles, and mechanical properties.

This study aims to investigate and compare the microstructure and some mechanical properties of two TiAl-based alloys with nominal composition Ti-42.6Al-8.7Nb-0.3Ta-2.0C and its derivative Ti-41.0Al-8.7Nb-0.3Ta-3.6C (in at.\%). The alloys differ in the content of $\mathrm{C}$, which was increased in the derivative alloy at the expense of a decrease in the content of Al. The effect of alloying on microstructure formation during solid-state phase transformations, microstructure stability during long-term ageing, hardness evolution, and creep behavior are reported and discussed.

\section{Results and Discussion}

\subsection{Solid-State Phase Transformations}

The alloys with nominal composition Ti-42.6Al-8.7Nb-0.3Ta-2.0C and Ti-41.0Al-8.7Nb-0.3Ta-3.6C (in at.\%) designated as C20 and C36, respectively, were prepared by vacuum induction melting in graphite crucibles followed by a centrifugal casting into a graphite mold. The as-cast alloys were subjected to hot isostatic pressing (HIP) at a temperature of $1260{ }^{\circ} \mathrm{C}$ to remove casting porosity. Table 1 summarizes the measured chemical composition of the studied alloys. The alloy C36 differs from the alloy C20 in the content of C, which is increased from 2.0 to 3.6 at.\% mainly at the expense of a decrease in the content of $\mathrm{Al}$ from 42.6 to 41.1 at.\%. The measured content of impurities such as oxygen and nitrogen do not exceed 800 wt.ppm and 100 wt.ppm, respectively. Figure 1a,b show the typical microstructure of differential thermal analysis (DTA) samples after cooling from a temperature of $1450{ }^{\circ} \mathrm{C}$ at a constant rate of $15{ }^{\circ} \mathrm{C} / \mathrm{min}$. Figure $1 \mathrm{c}$, d show the X-ray diffraction (XRD) patterns of the DTA samples indicating the presence of three coexisting phases: $\gamma$-TiAl (tetragonal crystal structure, $\mathrm{L1}_{0}$ ), $\alpha_{2}-\mathrm{Ti}_{3} \mathrm{Al}$ (ordered hexagonal crystal structure, $\mathrm{D} 0_{19}$ ), and $\mathrm{H}_{-} \mathrm{Ti}_{2} \mathrm{AlC}$ (hexagonal crystal structure, Pearson symbol hP8). Chemically, three different phases and two regions (lamellar and grain boundaries) can be identified in the microstructure of the studied alloys, as seen in Figure 1. Table 2 summarizes the measured chemical composition of the coexisting phases in the C20 and C36 alloys.

Table 1. Chemical composition of studied alloys (at.\%) and content of $\mathrm{O}$ and $\mathrm{N}$ (wt.ppm).

\begin{tabular}{cccccccc}
\hline Alloy & Ti & Al & Nb & Ta & C & O & N \\
\hline C20 & $46.4 \pm 0.4$ & $42.6 \pm 0.4$ & $8.7 \pm 0.1$ & $0.3 \pm 0.1$ & $2.0 \pm 0.1$ & $775 \pm 25$ & $84 \pm 15$ \\
C36 & $46.3 \pm 0.3$ & $41.1 \pm 0.4$ & $8.7 \pm 0.1$ & $0.3 \pm 0.1$ & $3.6 \pm 0.1$ & $760 \pm 30$ & $76 \pm 15$ \\
\hline
\end{tabular}




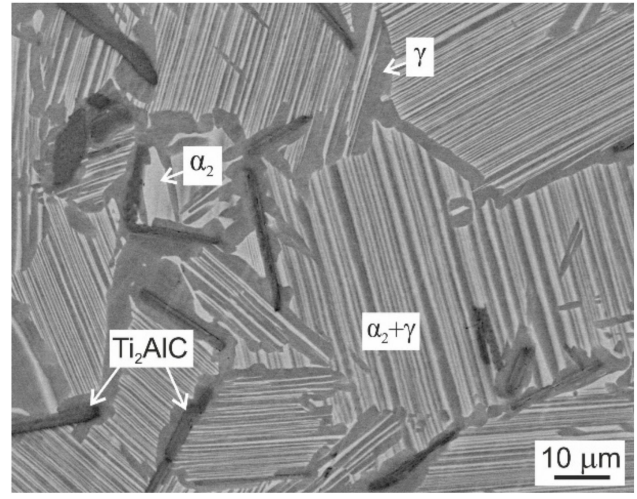

(a)

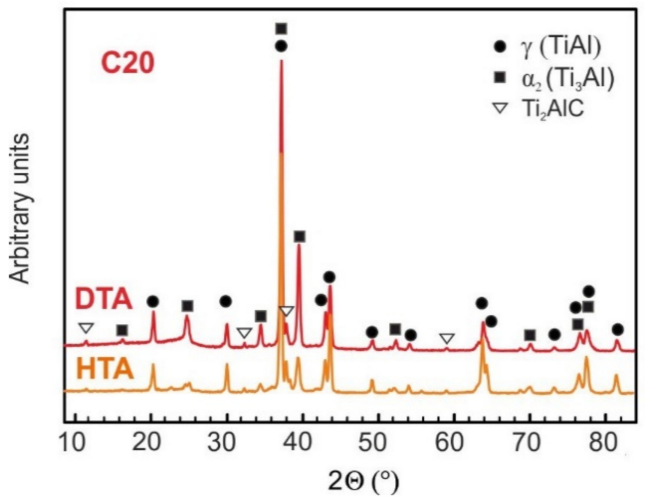

(c)

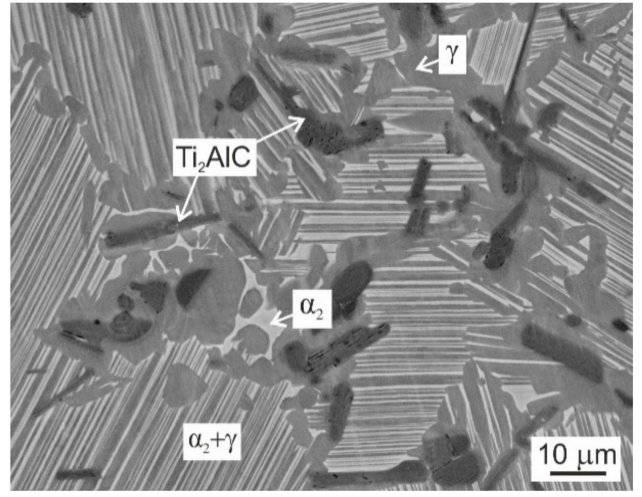

(b)

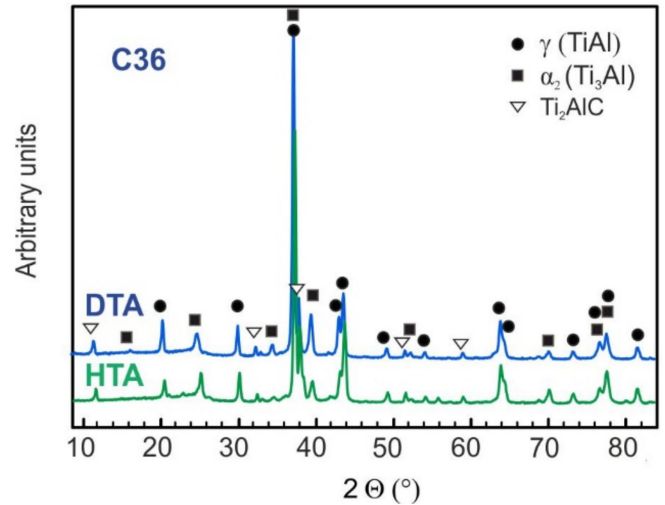

(d)

Figure 1. Microstructure and phase composition of DTA samples from C20 and C36 alloys after cooling from a temperature of $1450{ }^{\circ} \mathrm{C}$ at a rate of $15^{\circ} \mathrm{C} / \mathrm{min}$ : (a) BSE micrograph showing the microstructure of C20 alloy; (b) BSE micrograph showing the microstructure of C36 alloy; (c) The typical XRD patterns of C20 alloy; (d) The typical XRD patterns of C36 alloy.

Table 2. Chemical composition of coexisting phases and regions of the studied alloys (at.\%).

\begin{tabular}{ccccccc}
\hline Alloy & Phases & Ti & Al & Nb & Ta & C \\
\hline C20 & $\gamma$ & $44.5 \pm 0.3$ & $46.7 \pm 04$ & $8.7 \pm 0.1$ & $0.10 \pm 0.05$ & - \\
& $\alpha_{2}$ & $55.1 \pm 0.3$ & $35.6 \pm 0.4$ & $9.2 \pm 0.2$ & $0.10 \pm 0.05$ & - \\
& $\alpha_{2}+\gamma$ & $47.1 \pm 0.3$ & $43.8 \pm 0.4$ & $9.0 \pm 0.2$ & $0.10 \pm 0.05$ & - \\
& $\mathrm{Ti}_{2} \mathrm{AlC}$ & $40.8 \pm 0.5$ & $24.7 \pm 0.5$ & $5.9 \pm 0.2$ & $0.60 \pm 0.10$ & $28.0 \pm 0.4$ \\
C36 & $\gamma$ & $44.5 \pm 0.3$ & $46.9 \pm 0.4$ & $8.5 \pm 0.2$ & $0.10 \pm 0.05$ & - \\
& $\alpha_{2}$ & $54.6 \pm 0.4$ & $35.9 \pm 0.4$ & $9.3 \pm 0.2$ & $0.20 \pm 0.05$ & - \\
& $\alpha_{2}+\gamma$ & $47.0 \pm 0.3$ & $43.9 \pm 0.4$ & $9.0 \pm 0.2$ & $0.10 \pm 0.05$ & - \\
& $\mathrm{Ti}_{2} \mathrm{AlC}$ & $41.5 \pm 0.4$ & $24.5 \pm 0.4$ & $6.1 \pm 0.2$ & $0.60 \pm 0.10$ & $27.3 \pm 0.4$ \\
\hline
\end{tabular}

Based on the measured chemical composition and XRD analyses, the microstructure of the C20 alloy consists of equiaxed $\alpha_{2}+\gamma$ lamellar grains and grain boundaries containing single $\gamma$ phase, primary plate-like $\mathrm{Ti}_{2} \mathrm{AlC}$ particles and irregular shaped $\alpha_{2}$ phase, as seen in Figure 1a. The microstructure of the C36 alloy consists of equiaxed $\alpha_{2}+\gamma$ lamellar grains and wide grain boundaries containing $\gamma$ phase, coarse $\mathrm{Ti}_{2} \mathrm{AlC}$ particles, and irregular shaped $\alpha_{2}$ phase, as shown in Figure 1b. Table 2 indicates that $\mathrm{Nb}$ substitutes partially $\mathrm{Ti}$ atoms in $\mathrm{Ti}_{2} \mathrm{AlC}$ phase but its solubility reaches only $(0.69 \pm 0.03)$ of the average content of $\mathrm{Nb}$ in the studied alloys. This value is lower than that of $(0.78 \pm 0.06)$ reported by Klimova and Lapin [24] for intermetallic Ti-Al-Nb-C-Mo alloys reinforced with coarse primary $\mathrm{Ti}_{2} \mathrm{AlC}$ particles. On the other hand, the solubility of $\mathrm{Ta}$ in $\mathrm{Ti}_{2} \mathrm{AlC}$ is high and reaches $(1.95 \pm 0.03)$ of the average content of Ta in the C20 and C36 alloys. It should be mentioned that the morphology of the coarse primary $\mathrm{Ti}_{2} \mathrm{AlC}$ particles depends strongly on the content of $\mathrm{C}$. While the C20 alloy 
contains only long plate-like primary carbides, the C36 alloy contains both plate-like and numerous irregular shaped carbide particles formed preferentially along the lamellar grain boundaries, as seen in Figure $1 \mathrm{a}, \mathrm{b}$. Both plate-like and irregular shaped $\mathrm{Ti}_{2} \mathrm{AlC}$ particles are formed during solidification of the studied alloys according to the transformation pathway L (liquid) + $\mathrm{TiC}$ (face-centered cubic crystal structure, Pearson symbol $\mathrm{cF} 8) \rightarrow \mathrm{L}+\mathrm{Ti}_{2} \mathrm{AlC}[18,30]$. This reaction/transformation starts by the growth of solid $\mathrm{Ti}_{2} \mathrm{AlC}$ layer at the $\mathrm{L} / \mathrm{TiC}$ interfaces and leads to either full transformation of small TiC particles to $\mathrm{Ti}_{2} \mathrm{AlC}$ or the formation of continuous $\mathrm{Ti}_{2} \mathrm{AlC}$ layer around $\mathrm{TiC}$ clusters preserving the $\mathrm{TiC}$ phase in the cores of some irregular shaped carbide particles during fast cooling [17]. The retained TiC phase is unstable and transforms to the thermodynamically stable $\mathrm{Ti}_{2} \mathrm{AlC}$ phase during solution annealing in $\alpha$ (Ti-based solid solution with the hexagonal crystal structure, A3) or $\alpha+\beta$ (Ti-based solid solution with the cubic crystal structure, A2) phase fields [18,24].

Figure 2 shows the typical DTA curves of the C20 and C36 alloys obtained during cooling from a temperature of $1450{ }^{\circ} \mathrm{C}$ at a constant cooling rate of $15{ }^{\circ} \mathrm{C} / \mathrm{min}$. The DTA cooling curves, which are shifted vertically for clarity, indicate exothermic transformations. Two onset temperatures of the exothermic transformation represent the start and finish of the $\beta$ transformation to $\alpha$ phase according to phase transformation sequence $\beta+\mathrm{H} \rightarrow \beta+\alpha+\mathrm{H} \rightarrow \alpha+\mathrm{H}$. The onset start transformation temperature is slightly affected by the content of $\mathrm{C}$ and $\mathrm{Al}$ and increase from 1417 to $1425{ }^{\circ} \mathrm{C}$ with the increasing content of $\mathrm{C}$ from 2.0 to 3.6 at.\% and decreasing content of $\mathrm{Al}$ from 42.6 to 41.1 at.\%. The onset finish transformation temperature is not affected by the alloying and corresponds to 1349 and $1348{ }^{\circ} \mathrm{C}$ for the $\mathrm{C} 20$ and C36 alloy, respectively. As has been reported by several authors [31,32], high-temperature $\beta$ and $\alpha$ phases can be preserved in the microstructure by fast cooling. Figure 3 shows the microstructure of the C20 and C36 alloys after water quenching from a solution annealing temperature of $1400{ }^{\circ} \mathrm{C}$, which is below the $\beta$ to $\alpha$ phase start transformation temperature of 1417 and $1425^{\circ} \mathrm{C}$ in the C20 or C36 alloy, respectively. Three phases can be identified in the microstructure of the quenched samples: $\alpha$ (dark grey color phase), $\beta$ (white grey color phase), and $\mathrm{Ti}_{2} \mathrm{AlC}$ particles confirming $\beta+\alpha+\mathrm{H}$ phase field for both studied alloys at $1400{ }^{\circ} \mathrm{C}$. The onset temperatures of 1243 and $1164{ }^{\circ} \mathrm{C}$ and a 1268 and $1184{ }^{\circ} \mathrm{C}$ represent the start and finish of the $\alpha$ phase decomposition according to phase transformation sequence $\alpha+\mathrm{H} \rightarrow \alpha+\gamma+\mathrm{H}$ for the $\mathrm{C} 20$ and C36 alloy, respectively. Both the onset start and finish $\alpha$ phase decomposition temperatures are affected by the content of $C$ and $\mathrm{Al}$ and are lower for the $\mathrm{C} 20$ alloy compared to those of the $\mathrm{C} 36$ one. Below the finish $\alpha$ phase decomposition temperature, the phase transformation sequence $\alpha+\gamma+\mathrm{H} \rightarrow \alpha_{2}+\gamma+\mathrm{H}$ is identified in the studied alloys by XRD analysis, as seen in Figure 1c,d.

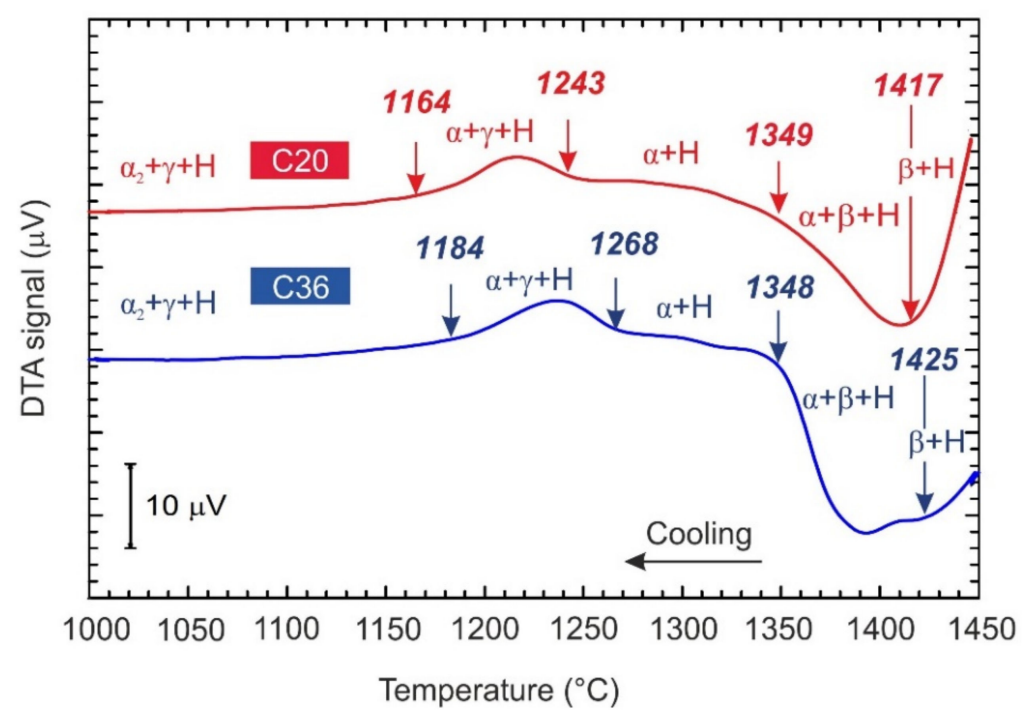

Figure 2. The typical DTA cooling curves of the studied C20 and C36 alloys. 


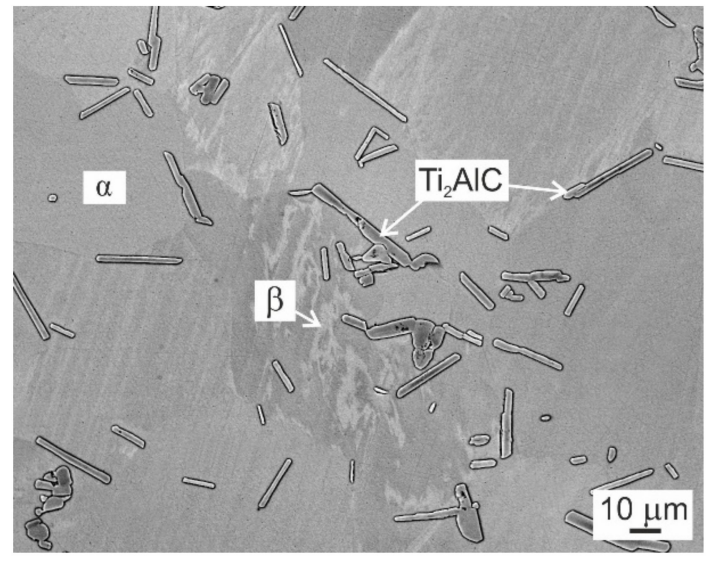

(a)

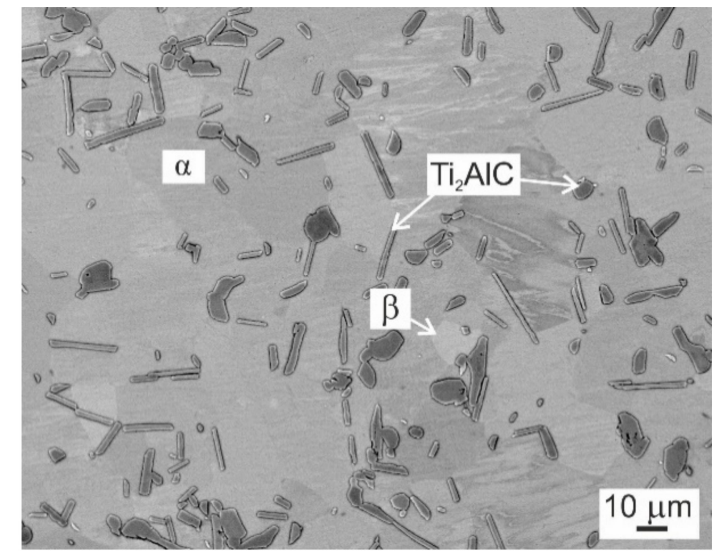

(b)

Figure 3. BSE micrographs showing the microstructure of the studied alloys after water quenching from a temperature of $1400{ }^{\circ} \mathrm{C}$ : (a) C20 alloy; (b) C36 alloy.

\subsection{Effect of Heat Treatment on Microstructure}

The C20 and C36 alloys used for the evaluation of microstructural stability and mechanical properties were subjected to the heat treatment after HIP-ing. The heat treatment consisted of solution annealing in the single $\beta$ phase field at a temperature of $1460^{\circ} \mathrm{C}$ followed by cooling at a constant cooling rate of $15^{\circ} \mathrm{C} / \mathrm{min}$ and stabilization annealing at $850{ }^{\circ} \mathrm{C}$ for $25 \mathrm{~h}$. Several authors $[12,15,16,19,27,33]$ have shown that the stabilisation annealing in a temperature range from 800 to $900{ }^{\circ} \mathrm{C}$ leads to the formation of fine secondary $\mathrm{P}-\mathrm{Ti}_{3} \mathrm{AlC}$ and $\mathrm{H}-\mathrm{Ti}_{2} \mathrm{AlC}$ precipitates along $\alpha_{2} / \gamma$ lamellar interfaces, which significantly improve the high temperature creep resistance of carbon-containing TiAl-based alloys. Figure 4 shows the typical microstructure of the heat-treated (HT) alloys. The microstructure of the HT C20 and HT C38 consists of fully lamellar $\alpha_{2}+\gamma$ grains separated by $\gamma$ grain boundaries containing $\mathrm{Ti}_{2} \mathrm{AlC}$ particles and irregular shaped $\alpha_{2}$ phase, as seen in Figure $4 \mathrm{a}-\mathrm{d}$. It should be noted that the chemical compositions of the coexisting phases and regions measured in the HT samples correspond to those of DTA samples (Table 2) and all deviations fall only within the experimental error of measurements. To compare the microstructure of the HT C20 and HT C36 alloys, microstructural parameters such as grain size, $\alpha_{2}-\alpha_{2}$ interlamellar spacing, size of primary carbide particles and volume fractions of lamellar grains, grain boundaries and primary carbide particles are measured and experimental data are evaluated statistically. Figure 5a shows that the measured data of grain size d (more than 1000 measurements) can be fitted by a log-normal distribution function. The statistical analysis leads to a mean grain size of $d=70.6 \pm 0.8 \mu \mathrm{m}$ for the HT C20 alloy, which is a significantly higher value than that of $\mathrm{d}=37.7 \pm 0.6 \mu \mathrm{m}$ measured for the HT C36 alloy. The statistical analysis of the measured $\alpha_{2}-\alpha_{2}$ interlamellar spacing $\lambda$ of the studied alloys (more than 2200 measurements for each alloy) shows that the best fit can be achieved by a log-normal distribution function, as seen in Figure $5 b$. The log-normal distribution curves result in a mean $\alpha_{2}-\alpha_{2}$ interlamellar spacing of $\lambda=0.62 \pm 0.01 \mu \mathrm{m}$ for the HT C20 alloy, which is a higher value than that of $\lambda=(0.54 \pm 0.01) \mu \mathrm{m}$ measured for the HT C36 alloy. Table 3 summarises the measured grain size $d, \alpha_{2}-\alpha_{2}$ interlamellar spacing $\lambda$, length of the major axis of $\mathrm{Ti}_{2} \mathrm{AlC}$ particles $\mathrm{L}$, volume fractions of lamellar grains $\mathrm{V}_{\mathrm{lg}}$ and grain boundaries $\mathrm{V}_{\mathrm{gb}}$, the volume fraction of primary $\mathrm{Ti}_{2} \mathrm{AlC}$ particles formed along the grain boundaries $\mathrm{V}_{\mathrm{Cgb}}$, and average volume fraction of $\mathrm{Ti}_{2} \mathrm{AlC}$ particles in the HT C20 and HT C 36 alloys $\mathrm{V}_{\mathrm{C}}$. The increase in the content of $\mathrm{C}$ at the expense of the decrease in the content of $\mathrm{Al}$ in the HT C36 alloy leads to a significant decrease in the volume fraction of lamellar grains to $\mathrm{V}_{\mathrm{lg}}=48 \mathrm{vol} . \%$ and increase in the volume fraction of grain boundaries to $\mathrm{V}_{\mathrm{gb}}=52$ vol. $\%$ compared to those of 72 and 28 vol.\%, respectively, in the HT C20 alloy. The higher content of $\mathrm{C}$ leads to the formation of a higher volume fraction of the primary $\mathrm{Ti}_{2} \mathrm{AlC}$ particles of $\mathrm{V}_{\mathrm{C}}=$ $14.1 \mathrm{vol} . \%$, which are preferentially distributed along the $\gamma$ grain boundaries achieving $\mathrm{V}_{\mathrm{Cgb}}=13.9$ vol. \% in the HT C36 alloy compared to those of $\mathrm{V}_{\mathrm{C}}=4.1 \mathrm{vol} . \%$ and $\mathrm{V}_{\mathrm{Cgb}}=3.4 \mathrm{vol} . \%$, respectively, 
measured in the HT C20 alloy. The formation of higher volume fraction of the primary $\mathrm{Ti}_{2} \mathrm{AlC} \mathrm{particles}$ in the HT C36 alloy leads to a decrease in mean length of their major axis to $\mathrm{L}=9.5 \mu \mathrm{m}$ compared to that of L $=10.8 \mu \mathrm{m}$ measured in the HT C20 alloy. Despite decreasing content of Al, the increasing content of C in the HT C36 alloy leads to the formation of wider grain boundaries composed of a higher volume fraction of the $\gamma$ phase (38.1 vol.\%) and primary $\mathrm{Ti}_{2} \mathrm{AlC}$ particles $(13.9 \mathrm{vol} . \%)$ compared to the grain boundaries of the $\mathrm{C} 20$ alloy containing 24.6 vol. $\%$ of $\gamma$ phase and 3.4 vol. $\%$ of $\mathrm{Ti}_{2} \mathrm{AlC}_{\text {particles. }}$

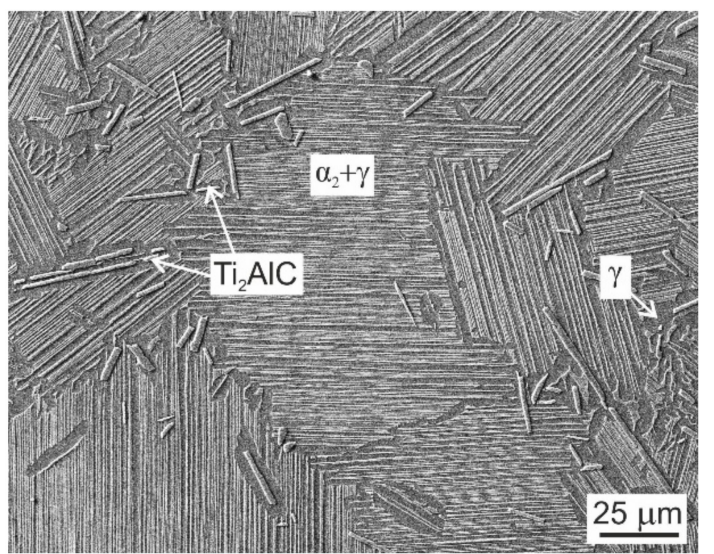

(a)

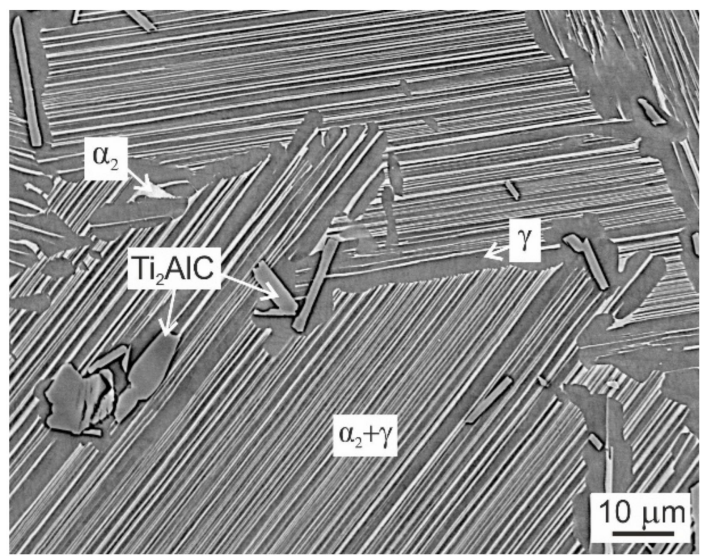

(c)

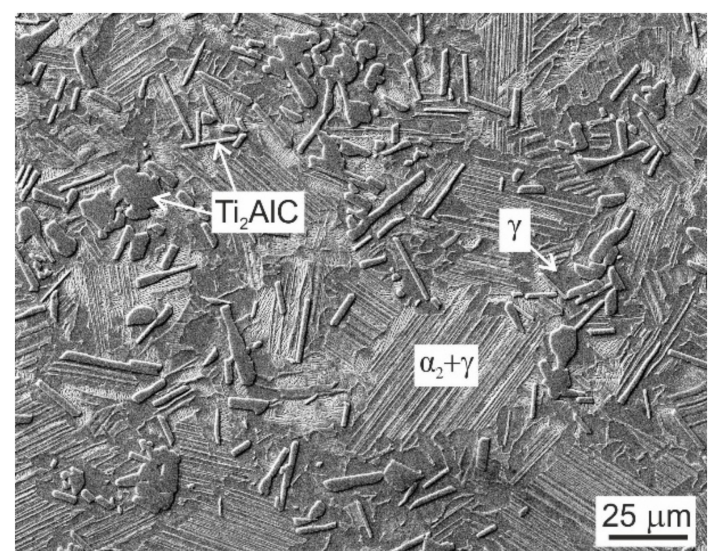

(b)

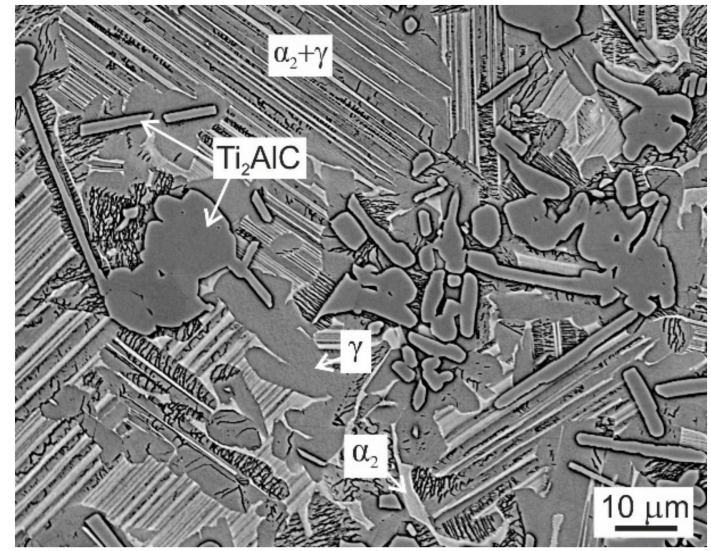

(d)

Figure 4. Micrographs showing the microstructure of C20 and C36 alloys after heat treatment: (a) Lamellar grain structure of HT C20 alloy, SEM; (b) Grain structure of HT C36 alloy, SEM; (c) Grain boundaries with $\gamma$ phase, primary $\mathrm{Ti}_{2} \mathrm{AlC}$ particles and $\alpha_{2}$ phase in HT C20 alloy, BSE; (d) Grain boundaries with $\gamma$ phase, primary $\mathrm{Ti}_{2} \mathrm{AlC}$ particles and $\alpha_{2}$ phase in HT C36 alloy, BSE. 


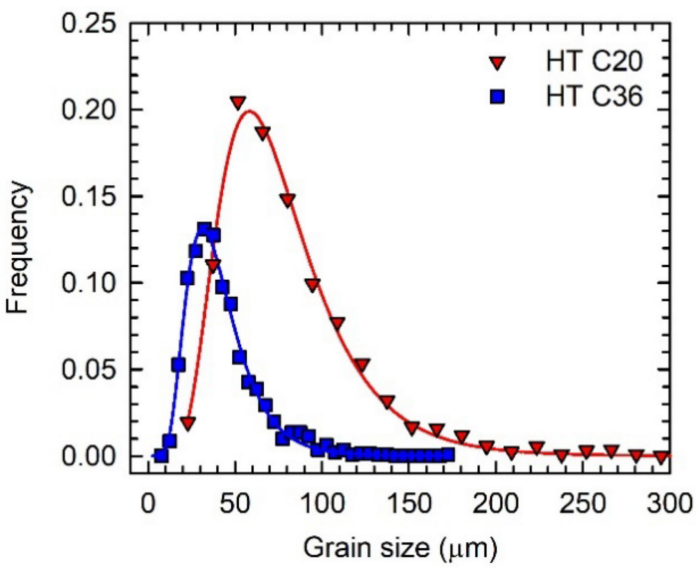

(a)

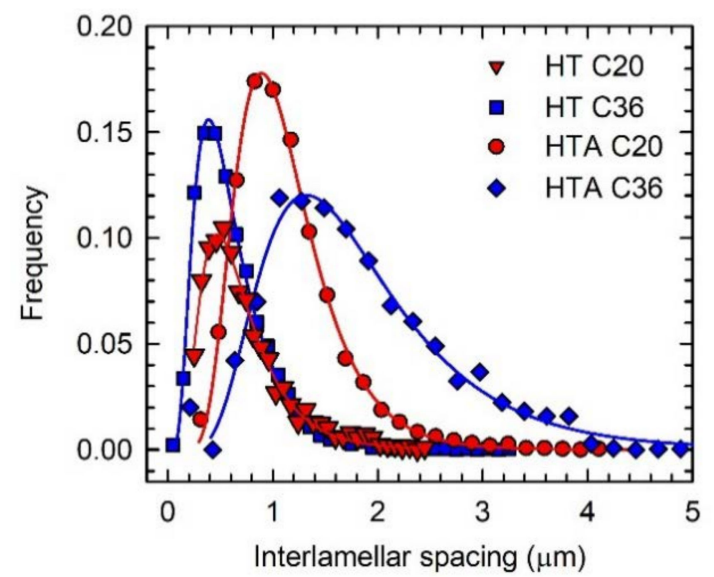

(b)

Figure 5. Measured grain size and interlamellar spacing in C20 and C36 alloys after heat treatment and heat treatment combined with ageing: (a) The typical log-normal distribution curves of grain size; (b) The typical log-normal distribution curves of $\alpha_{2}-\alpha_{2}$ interlamellar spacing. The types of distribution curves are marked in the figures.

Table 3. Measured microstructural parameters of C20 and C36 alloys after heat treatment and heat treatment combined with ageing.

\begin{tabular}{cccccccc}
\hline Alloy & $\begin{array}{c}\text { Grain Size } \\
\mathbf{d}(\mu \mathrm{m})\end{array}$ & $\begin{array}{c}\text { Interlamellar } \\
\text { Spacing } \lambda \\
(\mu \mathrm{m})\end{array}$ & $\begin{array}{c}\text { Major } \\
\text { Axis of } \\
\text { Carbides } \\
\mathbf{L}(\mu \mathrm{m})\end{array}$ & $\begin{array}{c}\text { Volume } \\
\text { Fraction } \\
\mathbf{V}_{\mathbf{l g}} / \mathbf{V}_{\mathbf{g b}} \\
\mathbf{( v o l . \% )}\end{array}$ & $\begin{array}{c}\text { Volume } \\
\text { Fraction } \\
\mathbf{V}_{\mathbf{C g b}} \\
(\mathbf{v o l . \% )}\end{array}$ & $\begin{array}{c}\text { Average } \\
\text { Volume } \\
\text { Fraction } \\
\mathbf{V}_{\mathbf{C}}(\mathbf{v o l} . \%)\end{array}$ \\
\hline C20 & HT & $70.6 \pm 0.8$ & $0.62 \pm 0.02$ & $10.8 \pm 0.2$ & $72 / 28$ & $3.4 \pm 0.2$ & $4.1 \pm 0.2$ \\
& HTA & $69.2 \pm 0.9$ & $1.04 \pm 0.02$ & $10.7 \pm 0.2$ & $68 / 32$ & $3.7 \pm 0.2$ & $4.2 \pm 0.2$ \\
C36 & HT & $37.7 \pm 0.6$ & $0.54 \pm 0.03$ & $9.5 \pm 0.4$ & $48 / 52$ & $13.9 \pm 0.4$ & $14.1 \pm 0.4$ \\
& HTA & $36.4 \pm 0.9$ & $1.66 \pm 0.03$ & $9.7 \pm 0.4$ & $39 / 61$ & $14.0 \pm 0.4$ & $14.2 \pm 0.4$ \\
\hline
\end{tabular}

\subsection{Effect of Ageing on Microstructure Stability}

Figure 6 shows the typical microstructure of the $\mathrm{C} 20$ and $\mathrm{C} 36$ alloys after ageing at $800{ }^{\circ} \mathrm{C}$ for $1240 \mathrm{~h}$. The microstructure of the heat-treated and aged (HTA) alloys consists of equiaxed $\alpha_{2}+$ $\gamma$ lamellar grains and grain boundaries containing single $\gamma$ phase reinforced with coarse primary $\mathrm{Ti}_{2} \mathrm{AlC}$ particles and a small amount of white color phase formed at the grain boundaries. However, the XRD patterns of the HTA alloys show the presence of only three phases: $\alpha_{2}, \gamma$ and $\mathrm{Ti}_{2} \mathrm{AlC}$, as seen Figure 1c,d. Table 4 summarizes the measured chemical composition of the coexisting phases and regions in the HTA alloys. Taking into account the measured chemical composition, temperature of the formation and assuming experimental study of ternary Ti-Al-Nb systems and more complex Ti-45Al-8.5Nb-0.2W-0.2B-0.02Y (at.\%) alloy reported by Witusiewicz et al. [34] and Wang et al. [35], respectively, the white color particles can be related to $\mathrm{Ti}_{4} \mathrm{NbAl}_{3}$ phase (hexagonal crystal structure, $\mathrm{B}_{2}$ ). The chemical composition of the coexisting phases in the HT (see Table 2) and HTA (see Table 4) alloys are slightly different. The main difference can be seen in the redistribution of $\mathrm{Nb}$, whose content is increased in the $\omega_{\mathrm{o}}-\mathrm{Ti}_{4} \mathrm{NbAl}_{3}$ particles at the expense of decreasing its amount in the $\gamma$ phase and $\alpha_{2}+\gamma$ lamellar regions. Since $\mathrm{Nb}$ is a low diffusing element in TiAl characterized by a diffusion coefficient of about $\mathrm{D}=4.56 \times 10^{-19} \mathrm{~m}^{2} / \mathrm{s}$ at $800^{\circ} \mathrm{C}$ [36], long-term ageing is required for the formation of $\omega_{\mathrm{o}}$ particles. Figures 1 and 4 clearly show that the $\omega_{\mathrm{o}}$ particles are not formed in the studied alloys during continuous cooling from the solution annealing temperature or during stabilization annealing at a temperature of $850{ }^{\circ} \mathrm{C}$ for $25 \mathrm{~h}$. The present results are in a good agreement with the experimental study and thermodynamic calculations of Witusiewicz et al. [34] showing that the $\mathrm{Ti}_{4} \mathrm{NbAl}_{3}$ is a stable 
phase at a temperature of $800{ }^{\circ} \mathrm{C}$ and decomposes according to a reaction $\mathrm{Ti}_{4} \mathrm{NbAl}_{3} \leftrightarrow \alpha_{2}+\gamma$ at a temperature higher than $810^{\circ} \mathrm{C}$.

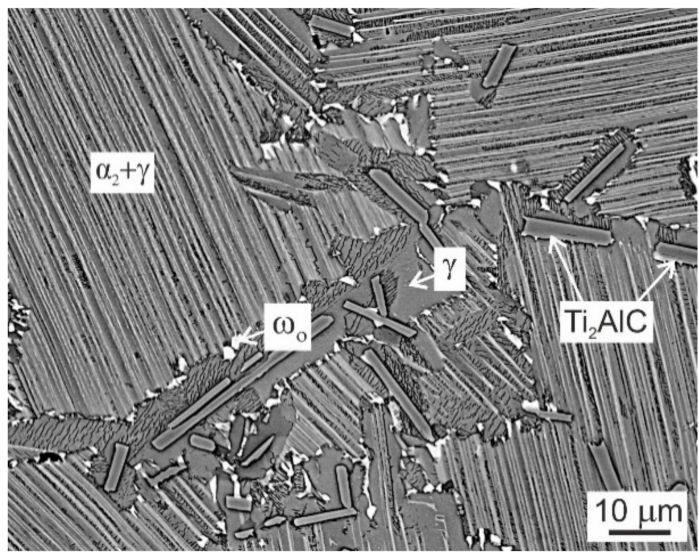

(a)

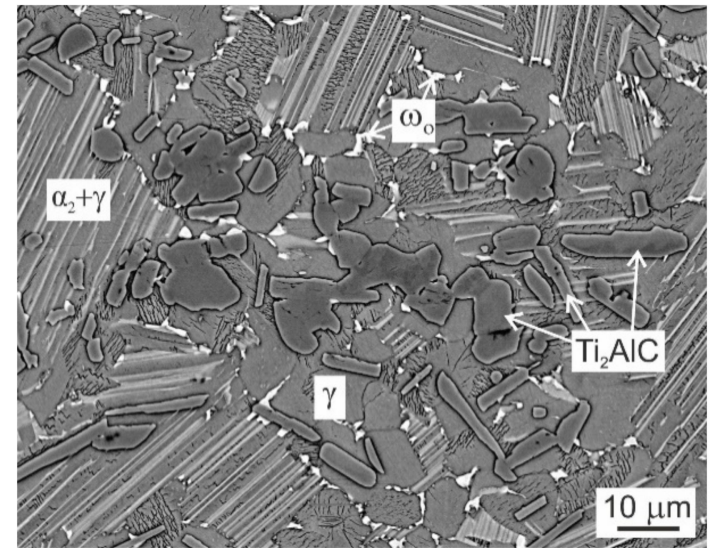

(b)

Figure 6. BSE micrographs showing the microstructure of C20 and C36 alloys after heat treatment combined with ageing: (a) HTA C20 alloy; (b) HTA C36 alloy. The coexisting phases and regions are marked in the figures.

Table 4. Chemical composition of coexisting phases in HTA C20 and HTA C36 alloys (at.\%).

\begin{tabular}{ccccccc}
\hline Alloy & Phases & Ti & Al & Nb & Ta & C \\
\hline \multirow{2}{*}{ HTA C20 } & $\gamma$ & $44.6 \pm 0.3$ & $46.9 \pm 0.3$ & $8.5 \pm 0.2$ & $0.10 \pm 0.05$ & - \\
& $\omega_{\mathrm{o}}$ & $50.5 \pm 0.3$ & $37.0 \pm 0.3$ & $12.3 \pm 0.2$ & $0.20 \pm 0.10$ & - \\
& $\alpha_{2}+\gamma$ & $47.1 \pm 0.3$ & $44.1 \pm 0.4$ & $8.7 \pm 0.3$ & $0.10 \pm 0.05$ & - \\
\multirow{2}{*}{ HTA C36 } & $\mathrm{Ti}_{2} \mathrm{AlC}$ & $40.6 \pm 0.4$ & $24.7 \pm 0.6$ & $5.9 \pm 0.2$ & $0.60 \pm 0.10$ & $28.2 \pm 0.4$ \\
& $\gamma$ & $44.4 \pm 0.3$ & $46.9 \pm 0.4$ & $8.6 \pm 0.2$ & $0.10 \pm 0.05$ & - \\
& $\omega_{\mathrm{o}}$ & $50.4 \pm 0.3$ & $37.1 \pm 0.4$ & $12.3 \pm 0.2$ & $0.20 \pm 0.10$ & - \\
& $\alpha_{2}+\gamma$ & $47.0 \pm 0.3$ & $44.2 \pm 0.4$ & $8.7 \pm 0.3$ & $0.10 \pm 0.05$ & - \\
& $\mathrm{Ti}_{2} \mathrm{AlC}$ & $40.8 \pm 0.4$ & $24.6 \pm 0.5$ & $6.0 \pm 0.2$ & $0.60 \pm 0.10$ & $28.0 \pm 0.5$ \\
\hline
\end{tabular}

Table 3 indicates that the long-term ageing at a temperature of $800{ }^{\circ} \mathrm{C}$ for $1240 \mathrm{~h}$ has no effect on the mean grain size $d$, mean length of major axis $L$ and average volume fraction of the primary $\mathrm{Ti}_{2} \mathrm{AlC}$ particles $\mathrm{V}_{\mathrm{C}}$ compared to those measured in the HT alloys. However, the mean interlamellar spacing $\lambda$ (see Figure 5b) increases significantly and the volume fraction of lamellar grains decreases in the HTA alloys compared to those in the HT ones, as summarized in Table 3. The increase in the $\alpha_{2}-\alpha_{2}$ interlamellar spacing can be attributed to the diffusion-controlled lateral growth of the $\gamma$ lamellae at the expense of dissolution of $\alpha_{2}$ lamellae [37,38]. In carbon-containing TiAl-based alloys, the widening of $\gamma$ lamellae is hindered by the carbon atoms, which segregate to ledges and kinks at $\alpha_{2} / \gamma$ lamellar interfaces and form fine secondary $\mathrm{P}-\mathrm{Ti}_{3} \mathrm{AlC}$ or $\mathrm{H}-\mathrm{Ti}_{2} \mathrm{AlC}$ precipitates $[27,39]$.

\subsection{Vickers Hardness and Elastic Modulus}

Figure 7 shows Vickers hardness $\mathrm{HV}$ and Vickers microhardness of lamellar grains $\mathrm{HV}_{\mathrm{m}}$ of the C20 and C36 alloys after heat treatment and heat treatment combined with ageing. The increase in the content of $\mathrm{C}$ and decrease in the content of Al in the HT C36 alloy have no significant effect on the HV values compared to that of HT C20 alloy and all deviations fall into the error of measurements. The long-term ageing leads to a small decrease in HV values by about $4 \%$ but no statistical differences can be found between HT C20 and HTA C36 samples, as shown in Figure 7a. Figure 7b shows Vickers microhardness $\mathrm{HV}_{\mathrm{m}}$ of the $\alpha_{2}+\gamma$ lamellar grains. The microhardness of the HT C36 sample is higher than that of the HT C20 one, which can be explained by a finer lamellar structure of the C36 alloy (see 
Table 3). As shown by Lapin [40], Vickers microhardness $H V_{m}$ increases with decreasing interlamellar spacing $\lambda$ according to the relationship $H_{\mathrm{m}} \propto 1 / \sqrt{\lambda}$. The long-term ageing leads to a decrease of $\mathrm{HV}_{\mathrm{m}}$ values in both HTA C20 and HTA C36 alloys, which can be related to an increase in interlamellar spacing $\lambda$ (see Table 3).

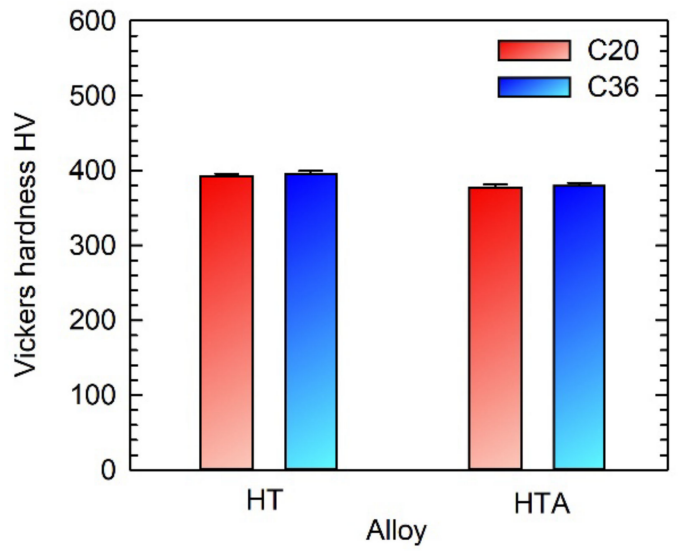

(a)

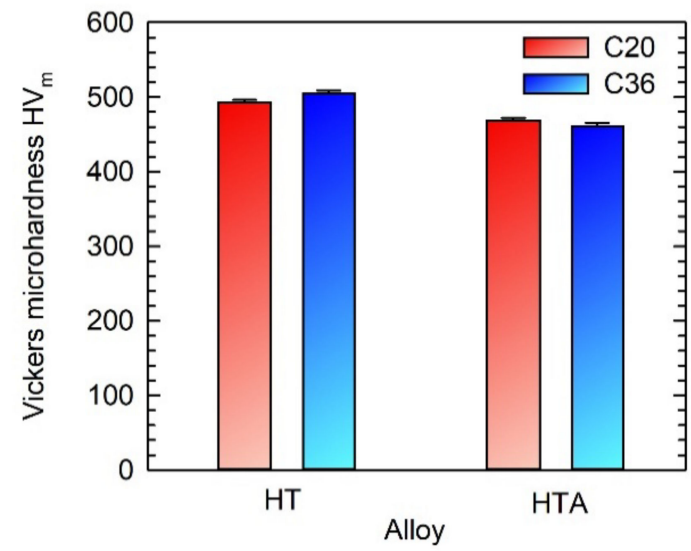

(b)

Figure 7. (a) Vickers hardness HV and (b) Vickers microhardness of lamellar grains $\mathrm{HV}_{\mathrm{m}}$ of $\mathrm{C} 20$ and C36 alloys after heat treatment and heat treatment combined with ageing. The type of alloys and applied treatments are marked in the figures.

Figure 8 shows indenation nanohardness and indentation elastic modulus of the $\gamma$ phase and primary $\mathrm{Ti}_{2} \mathrm{AlC}$ particles formed along the grain boundaries in the C20 and C36 alloys. The increase in the content of $\mathrm{C}$ and decrease in the content of Al in the HT C36 alloy have no statistical effect on indentation nanohardness and elastic modulus measured in the $\gamma$ phase formed along the grain boundaries compared to those of the HT C20 alloy. The nanohardness of the $\gamma$ phase is evaluated to be $(8.2 \pm 0.3) \mathrm{GPa}$ in both alloys, which is a comparable value with that of $8.5 \mathrm{GPa}$ but higher than that of $6.8 \mathrm{GPa}$ reported for Ti-43.7Al-4.1Nb-1.1Mo-0.1B-0.78C and Ti-43.5Al-4Nb-1Mo-0.1B (at.\%) alloys, respectively [41,42]. The high nanohardness values of the $\gamma$ phase can be related to its solution hardening by $C$, whose solubility has been measured to be up to 0.3 at.\% [41]. The long-term ageing leads to a decrease of indentation nanohardness and elastic modulus of the boundary $\gamma$ phase in the HTA C20 and HTA C36 alloys, as seen in Figure 8a,b. The decrease of nanohardness can be attributed to the formation of secondary carbide precipitates and local recovery and/or recrystallization of the $\gamma$ phase [27]. Figure 8c,d indicate that the chemical composition and applied heat treatment have no statistical effect on the indentation nanohardness and indentation elastic modulus of coarse primary $\mathrm{Ti}_{2} \mathrm{AlC}$ particles. The measured elastic modulus of $(247 \pm 6) \mathrm{GPa}$ is comparable with the values ranging from 245 to $260 \mathrm{GPa}$ reported for $\mathrm{Ti}_{2} \mathrm{AlC}$ by Velasco et al. [43]. 


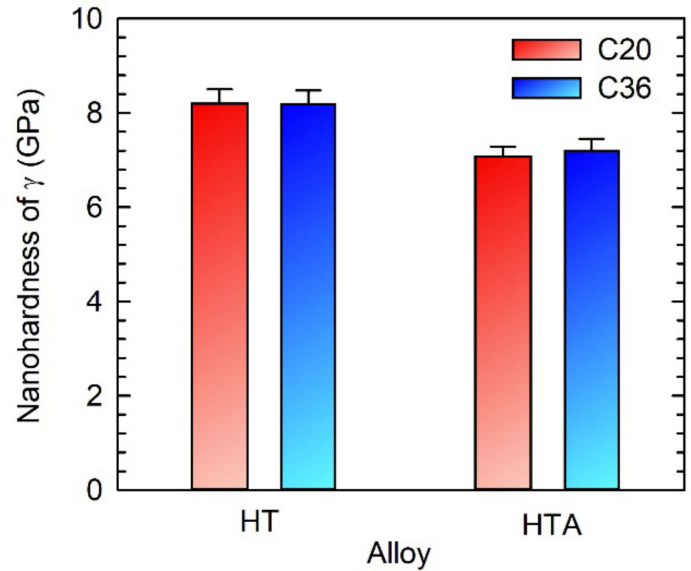

(a)

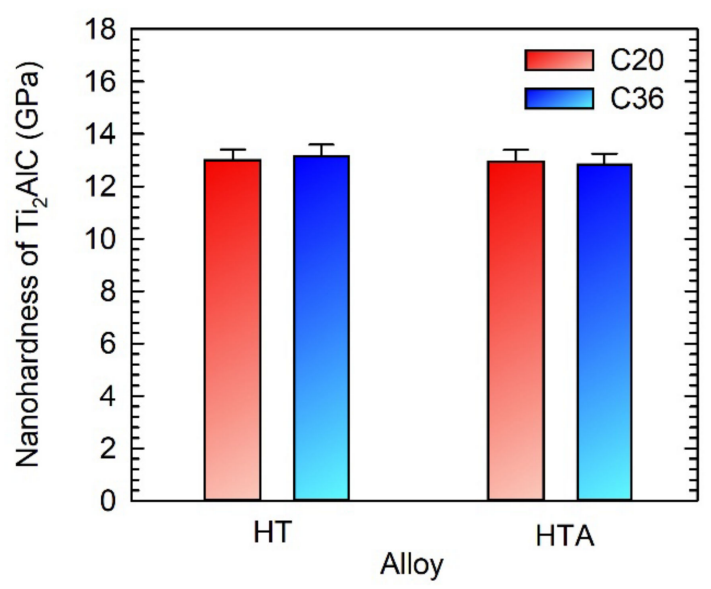

(c)

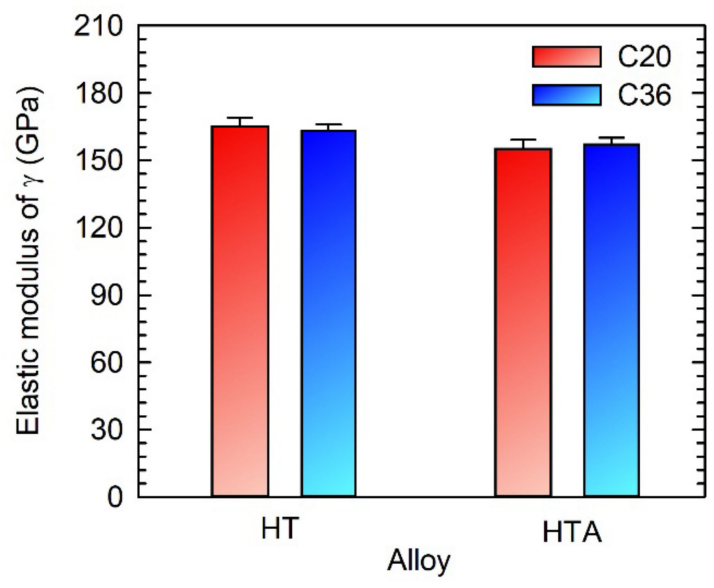

(b)

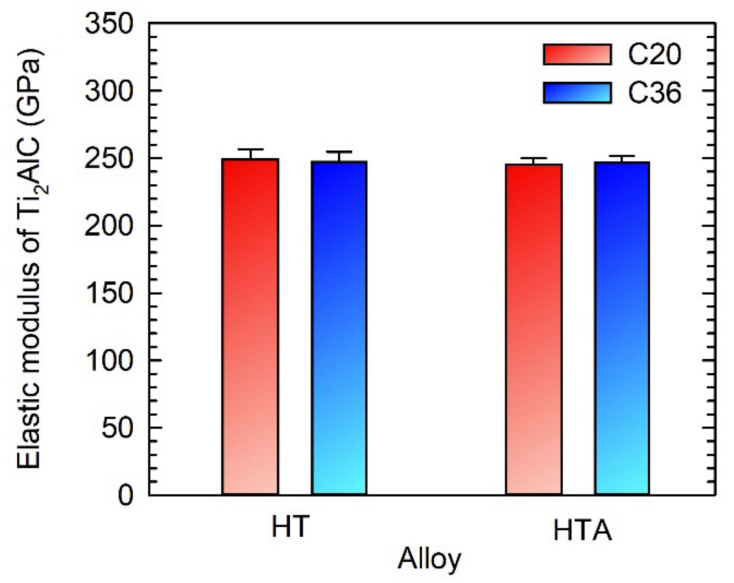

(d)

Figure 8. Indentation nanonahardness and elastic modulus of C20 and C36 alloys after heat treatment and heat treatment combined with ageing: (a) Indentation nanohardness of grain boundary $\gamma$ phase; (b) Indentation elastic modulus of grain boundary $\gamma$ phase; (c) Indentation nanohardness of primary $\mathrm{Ti}_{2} \mathrm{AlC}$ particles; (d) Indentation elastic modulus of primary $\mathrm{Ti}_{2} \mathrm{AlC}$ particles. The type of alloys and applied treatments are marked in the figures.

\subsection{Creep Behaviour}

Figure 9 shows tensile creep deformation curves for the HT alloys at a temperature of $800{ }^{\circ} \mathrm{C}$ and applied stress of $200 \mathrm{MPa}$. While the creep of the C20 alloy was interrupted after $1240 \mathrm{~h}$ corresponding to a strain of $6.2 \%$, the C 36 alloy was tested up to a creep fracture achieved after $610 \mathrm{~h}$ at a strain of $22.4 \%$, as shown in Figure 9a. The creep deformation curves indicate an improved creep resistance of the $\mathrm{C} 20$ alloy compared to that of the C36 one. Both creep curves exhibit primary creep stage, which is directly followed by the tertiary creep, as seen in Figure 9b. During the primary creep stage, the creep rate decreases to a minimum value of $9.9 \times 10^{-9} \mathrm{~s}^{-1}$ at a strain of $1.8 \%$ and $3.31 \times 10^{-8} \mathrm{~s}^{-1}$ at a strain of $1.3 \%$ and then increases with increasing strain in the C20 and C36 alloy, respectively. Besides lower minimum creep rate, a significantly improved creep resistance of the $\mathrm{C} 20$ alloy can be observed during whole creep deformation. After the creep for $610 \mathrm{~h}$, the creep strain achieves only $2.8 \%$ in the $\mathrm{C} 20$ alloy compared to that of $22.4 \%$ in the C 36 one. The tertiary creep stage is characterized by an increase in the creep strain and creep rate and results from the degradation of the initial HT microstructure of the studied alloys. 


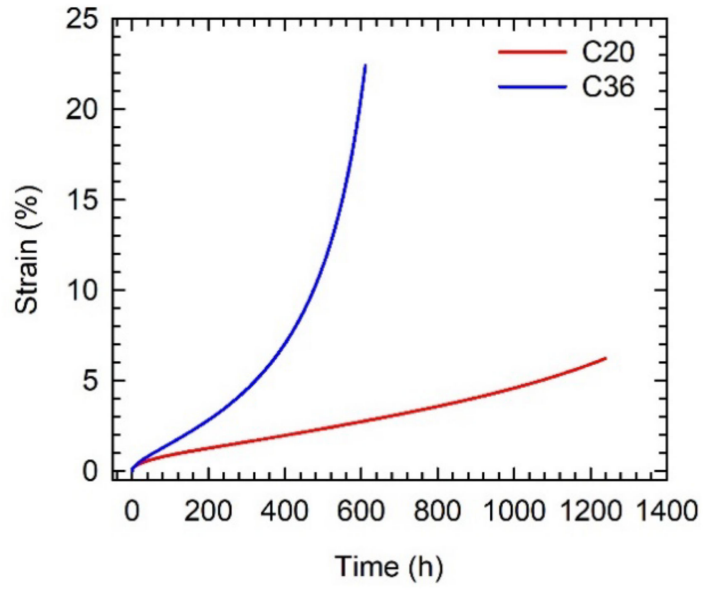

(a)

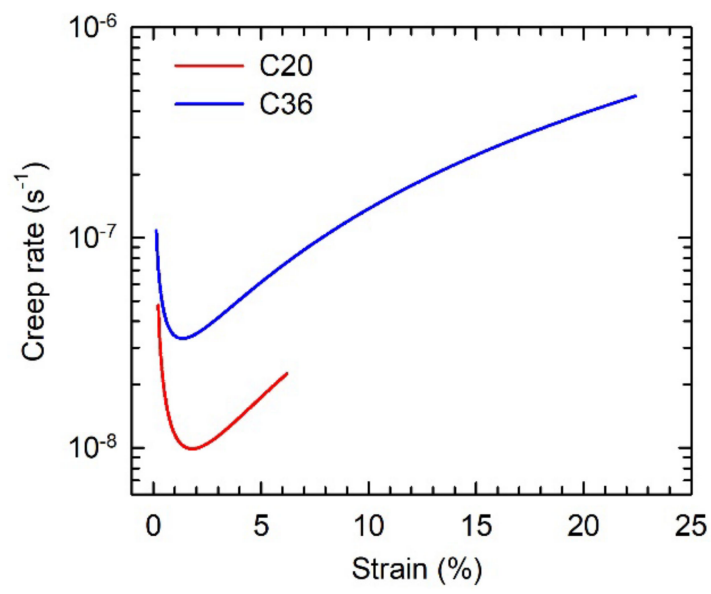

(b)

Figure 9. Creep deformation curves of $\mathrm{C} 20$ and C36 alloys at a temperature of $800{ }^{\circ} \mathrm{C}$ and applied stress of 200 MPa: (a) Dependence of creep strain on time; (b) Dependence of creep rate on strain. The studied alloys are indicated in the figures.

Figure 10 shows the typical microstructures of the C20 and C36 creep specimens tested to a strain of 6.2 and $22.4 \%$, respectively. Figure 10a,b indicate that the deformed lamellar grains of the C20 alloy contain relatively stable $\alpha_{2}$ lamellae and the primary plate-like $\mathrm{Ti}_{2} \mathrm{AlC}$ particles are not fragmented and pin effectively the grain boundaries. The main microstructural instabilities can be related to the formation of numerous $\omega_{\mathrm{o}}$ particles and cavities of various size along the lamellar grain boundaries. The cavitation along the grain boundaries strongly depends on the orientation of the neighboring grains. The soft oriented grains have lamellae inclined at an angle of $35^{\circ}$ or $75^{\circ}$ and hard oriented grains have lamellae parallel or perpendicular to the stress axis [44]. The cavities formed along the hard/hard oriented grains are usually larger in size than those formed between the soft/hard oriented grains [10]. The creep of the C36 alloy is accompanied by bending and fragmentation of some plate-like and irregular shaped $\mathrm{Ti}_{2} \mathrm{AlC}$ particles, the formation of numerous $\omega_{\mathrm{o}}$ particles, and widening of the grain boundaries at the expense of decreasing volume fraction of lamellar colonies. The $\omega_{\mathrm{o}}$ phase is preferentially formed along the grain boundaries and frequently at $\mathrm{Ti}_{2} \mathrm{AlC} / \mathrm{matrix}$ interfaces, as shown in Figure 10c,d. The $\omega_{\mathrm{o}}$ particles formed along the grain boundaries interlock the neighboring grains, reduce effectively grain boundary sliding, and improve fracture resistance by preventing the formation of grain boundary wedge cracks. The formation of the $\gamma+\omega_{\mathrm{o}}+\mathrm{Ti}_{2} \mathrm{AlC}$ type of microstructure along the grain boundaries between the soft/hard and hard/hard oriented grains affects significantly the cavitation mechanisms and fracture resistance of the $\mathrm{C} 36$ alloy. The deformation occurring continuously in the soft boundary $\gamma$ phase leads to the nucleation and coalescence of the cavities. The growth of cavities formed along the grain boundaries is controlled by diffusion and strongly affected by the creep induced formation of secondary phases $[45,46]$. The fracture of the C36 alloy occurs due to overloading with the fracture path propagating preferentially intergranularly, as seen in Figure 10c. 


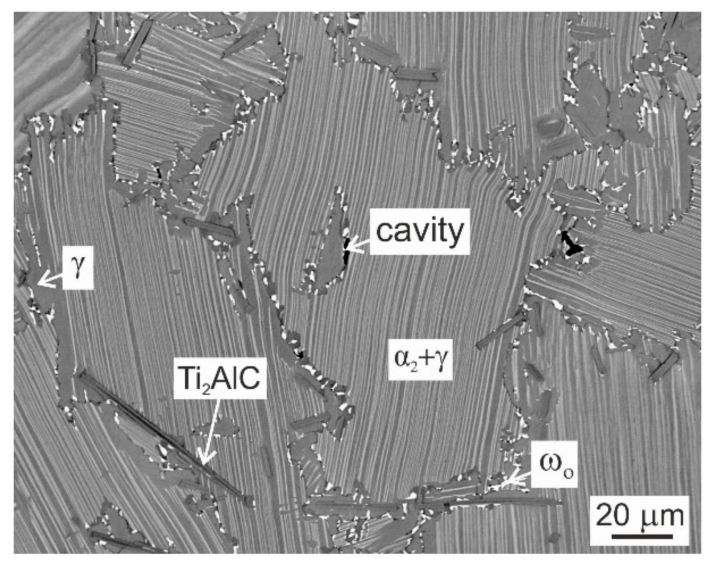

(a)

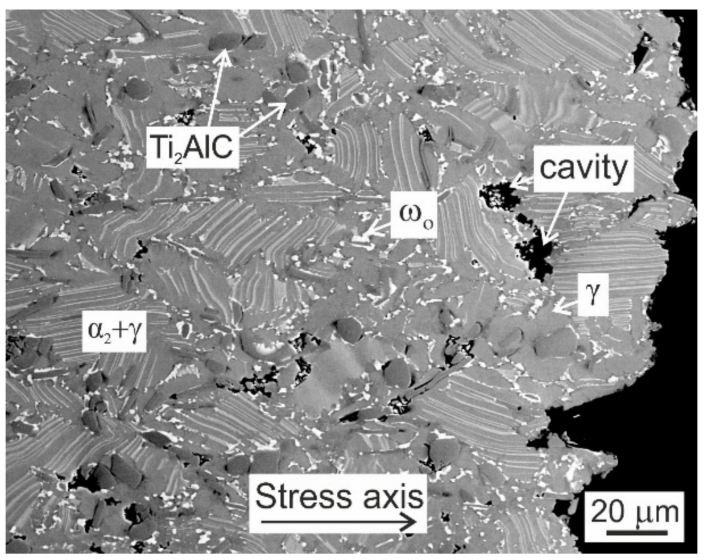

(c)

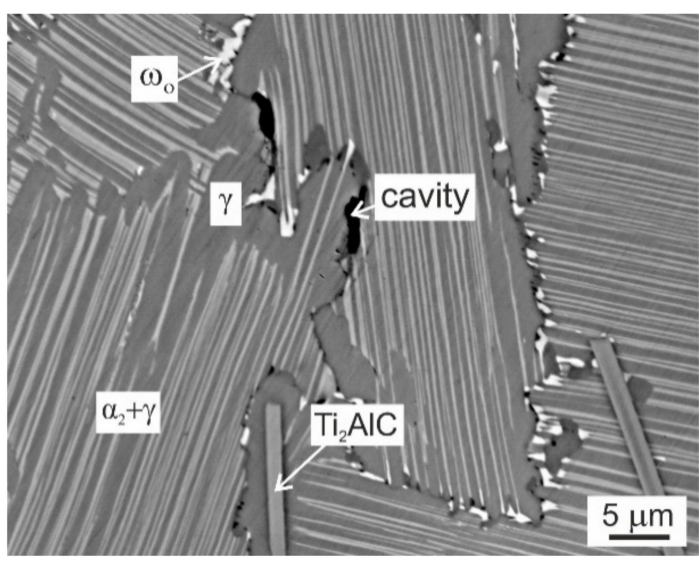

(b)

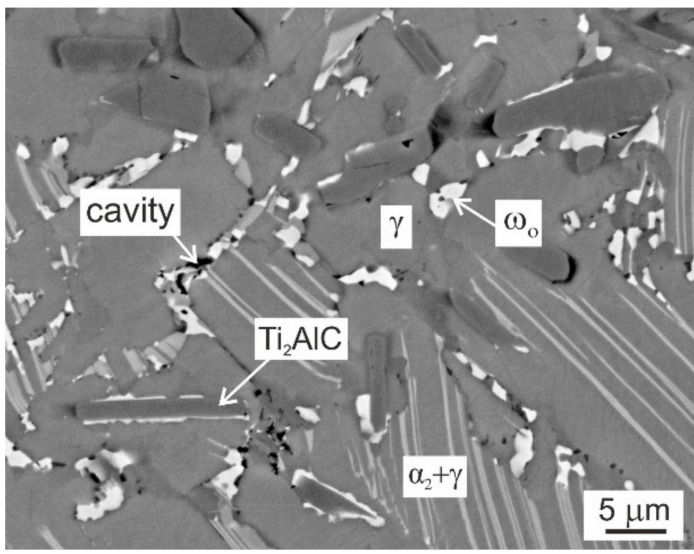

(d)

Figure 10. BSE micrographs showing longitudinal sections of C20 and C36 alloys after creep testing at a temperature of $800{ }^{\circ} \mathrm{C}$ and applied stress of $200 \mathrm{MPa}$ : (a,b) Microstructure of the C20 creep specimen tested to a strain of $6.2 \%$ for $1240 \mathrm{~h}$; (c,d) Microstructure of the C36 creep specimen tested to a fracture for $610 \mathrm{~h}$.

Figure 11 shows creep deformation curves of the C20 and C 36 alloys compared to those of other TiAl-based alloys tested at a temperature of $800^{\circ} \mathrm{C}$ and applied stress of $200 \mathrm{MPa}$. The studied C20 alloy shows more extended primary creep stage and similar creep resistance up to a strain of $4 \%$ compared to those of Ti-46.4Al-5.1Nb-1C-0.2B (at.\%) alloy with fully lamellar microstructure reinforced with 2.3 vol. $\%$ of coarse primary $\mathrm{Ti}_{2} \mathrm{AlC}$ particles [5], as shown in Figure 11a,b. The creep resistance of the C20 alloy is improved compared to that of the studied C36 alloy or reference alloys (in at.\%) such as Ti-45Al-2W-0.6Si-0.7B with nearly lamellar structure [13], Ti-46Al-8Ta with convoluted structure [10,47], Ti-46Al-2W-0.5Si with pseudo-duplex structure [48], and Ti-44.6Al-7.9Nb-3.6C-0.7Mo-0.1B with $\gamma$ matrix reinforced with 14.6 vol. $\%$ of coarse primary $\mathrm{Ti}_{2} \mathrm{AlC}$ particles and fine secondary $\mathrm{P}^{-\mathrm{Ti}_{3} \mathrm{AlC}}$ and $\mathrm{H}-\mathrm{Ti}_{2} \mathrm{AlC}$ precipitates [27]. The improvement in the creep strength of the $\mathrm{C} 20$ alloy can be attributed to the stabilization of the fully lamellar $\alpha_{2}+\gamma$ structure and its reinforcement with plate-like primary $\mathrm{Ti}_{2} \mathrm{AlC}$ particles as well as with fine secondary $\mathrm{P}-\mathrm{Ti}_{3} \mathrm{AlC}$ and $\mathrm{H}-\mathrm{Ti}_{2} \mathrm{AlC}$ precipitates forming in carbon-containing TiAl-based alloys during heat treatment and creep exposure $[12,15,27,33,49]$. The C36 alloy shows comparable creep strength to that of Ti-45Al-2W-0.6Si-0.7B (at.\%) alloy with nearly lamellar structure containing numerous ribbon-like boride particles and $\mathrm{Ti}_{5} \mathrm{Si}_{3}$ precipitates [13]. The improved creep resistance of the C36 alloy compared to Ti-44.6Al-7.9Nb-3.6C-0.7Mo-0.1B (at.\%) alloy with single $\gamma$ phase matrix reinforced with carbide particles [27] can be attributed to the presence of $\alpha_{2}+\gamma$ lamellar colonies and larger grain size of the studied C36 alloy. As reported by Maruyama et al. [50] or Kim 
and Kim [51], because of easy dynamic recrystallization, creep rate of fully lamellar TiAl-based alloys is independent of grain size larger than about $100 \mu \mathrm{m}$. However, room temperature ductility decreases with increasing grain size [6].

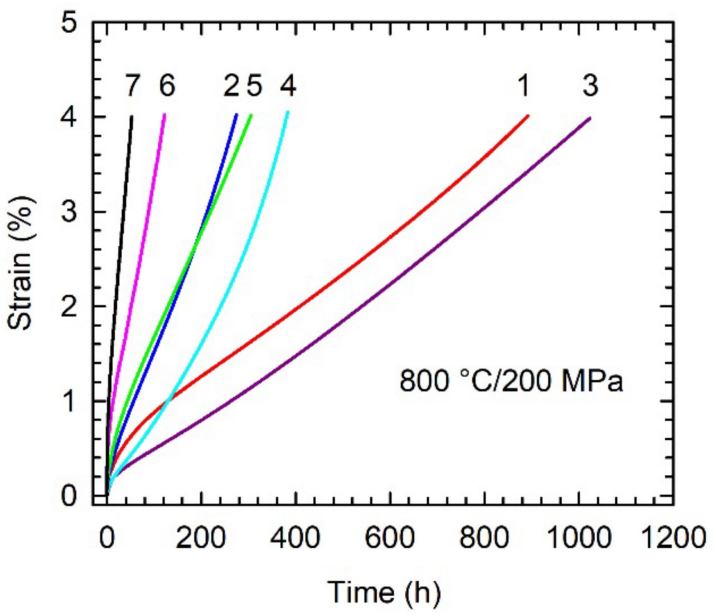

(a)

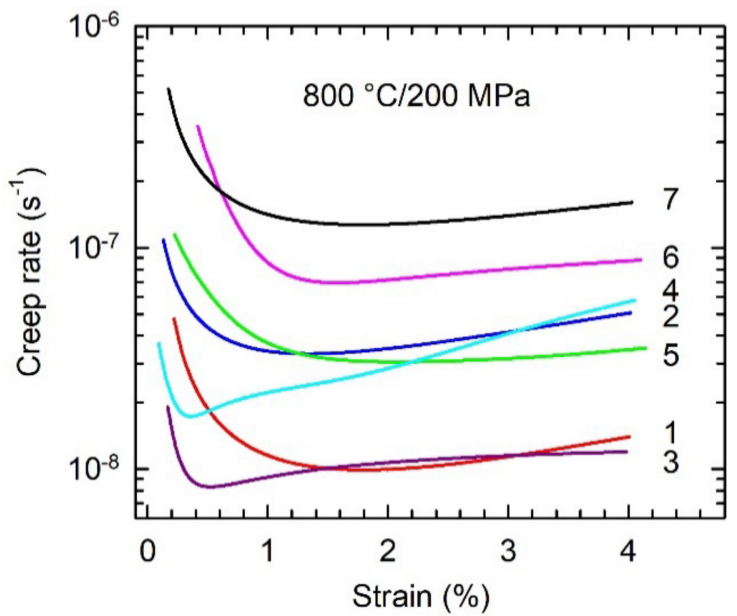

(b)

Figure 11. Creep deformation curves at a temperature of $800{ }^{\circ} \mathrm{C}$ and applied stress of $200 \mathrm{MPa}$ : (a) Dependence of creep strain on time; (b) Dependence of creep rate on strain. Designation and composition of reference alloys (in at.\%): 1-studied C20 alloy, 2-studied C36 alloy, 3-Ti-46.4Al-5.1Nb-1C-0.2B, 4-Ti-46Al-8Ta, 5-Ti-45Al-2W-0.6Si-0.7B, 6-Ti-46Al-2W-0.5Si and 7-Ti-44.6Al-7.9Nb-3.6C-0.7Mo-0.1B.

\section{Materials and Methods}

The studied TiAl-based alloys with designed nominal composition Ti-42.6Al-8.7Nb-0.3Ta-2.0C and Ti-41.0Al-8.7Nb-0.3Ta-3.6C (at.\%) were prepared by vacuum induction melting of pure metals (purity 99.99\%) and addition of graphite powder in graphite crucibles and centrifugally cast into graphite mold using the procedure described elsewhere [18,52]. The conical as-cast samples with a minimum diameter of $12 \mathrm{~mm}$, maximum diameter of $15 \mathrm{~mm}$ and length of $150 \mathrm{~mm}$ were subjected to HIP at a temperature of $1260{ }^{\circ} \mathrm{C}$ and applied pressure of $200 \mathrm{MPa}$ for $4 \mathrm{~h}$ in a protective argon atmosphere. Heat treatment of the HIP-ed samples consisted of solution annealing at a temperature of $1460{ }^{\circ} \mathrm{C}$ for $50 \mathrm{~min}$ and cooling at a constant rate of $15^{\circ} \mathrm{C} / \mathrm{min}$ to a temperature of $600{ }^{\circ} \mathrm{C}$ and furnace cooling to room temperature under protective argon atmosphere. The heat treatment was finalized by stabilization annealing at a temperature of $850{ }^{\circ} \mathrm{C}$ for $25 \mathrm{~h}$ in air. During heat treatment, the temperature of the samples was measured by PtRh10-Pt thermocouple (type S, Omega, CT, USA) touching the sample surface. The HT samples were cut transversally to a length of $10 \mathrm{~mm}$ and subjected to long-term isothermal ageing at a temperature of $800{ }^{\circ} \mathrm{C}$ for $1240 \mathrm{~h}$.

Solid-state phase transformation temperatures were determined by DTA in alumina crucibles using alumina powder as the reference standard. The DTA samples were cut from the HT samples by electro spark machining and lathe machined to a diameter of $6 \mathrm{~mm}$ and length of $6 \mathrm{~mm}$. The samples were heated to a temperature of $1450{ }^{\circ} \mathrm{C}$ at a heating rate of $15{ }^{\circ} \mathrm{C} / \mathrm{min}$, hold at this temperature for $10 \mathrm{~min}$ and then cooled to room temperature at a cooling rate of $15{ }^{\circ} \mathrm{C} / \mathrm{min}$ under protective argon atmosphere. The maximum sample temperature was selected below the onset of the solidus temperatures of the studied alloys to avoid reactions between the melt and alumina crucible [53]. In this study, the phase transformation temperatures were determined only from the cooling DTA curves.

Vickers hardness measurements were carried out at an applied load of $298 \mathrm{~N}$, holding time at the point of load application of $10 \mathrm{~s}$ and rate of load application of $10 \mathrm{~N} / \mathrm{s}$ on HT and HTA samples. Vickers microhardness measurements of lamellar grains were performed at an applied load 
of $0.49 \mathrm{~N}$ and dwell time of $10 \mathrm{~s}$ on polished and slightly etched sections of the HT and HTA samples. Instrumented nanoindentation measurements of the coexisting phases were carried out at an applied load of $0.01 \mathrm{~N}$ and holding time at the point of load application of $2 \mathrm{~s}$ on polished and slightly etched samples using a nanoindenter with Berkovich tip of the indenter.

Cylindrical creep specimens with a gauge diameter of $6 \mathrm{~mm}$ and a gauge length of $30 \mathrm{~mm}$ were lathe machined from HT samples. Constant load tensile creep tests were carried out at a temperature of $800^{\circ} \mathrm{C}$ under an initial stress of $200 \mathrm{MPa}$ in air. The test temperature was monitored with two thermocouples touching the specimen gauge section and held constant within $\pm 1{ }^{\circ} \mathrm{C}$. Elongation was measured using a high-temperature extensometer attached to the ledges of the creep specimen. The extensometer was equipped with a linear variable displacement transformer (LVDT). The acquisition of time-elongation data was accomplished by a computer and data processing was performed by a computer program.

Metallographic preparation of the samples consisted of standard grinding using abrasive papers, polishing on diamond pastes with various grain size up $1 \mu \mathrm{m}$ and etching in a solution of $100 \mathrm{~mL} \mathrm{H}_{2} \mathrm{O}$, $6 \mathrm{~mL} \mathrm{HNO}_{3}$, and $3 \mathrm{~mL} \mathrm{HF}$. Microstructure evaluation was performed by scanning electron microscopy in secondary electron (SEM) and back-scattered electron (BSE) modes using JEOL JSM-7600F microscope (JEOL, Tokyo, Japan). The chemical composition of the samples was evaluated by energy-dispersive spectrometry (EDS). The EDS system applied for measurements of chemical compositions of carbide particles was calibrated using standards. The average oxygen and nitrogen content was measured by LECO ONH836 elemental analyzer. The average carbon content was determined by LECO CS844 elemental analyzer. X-ray diffraction (XRD) analysis was carried out by a Bruker D8 Discover diffractometer (Billerica, MA, USA) equipped with X-ray tube with rotating $\mathrm{Cu}$ anode operating at $12 \mathrm{~kW}$. The volume fraction of phases, grain size, size of carbide particles, and interlamellar spacing were measured by computerized image analysis using digitalized micrographs and the measured data were treated statistically.

\section{Conclusions}

The microstructure and mechanical properties of two TiAl-based alloys with nominal composition Ti-42.6Al-8.7Nb-0.3Ta-2.0C and Ti-41.0Al-8.7Nb-0.3Ta-3.6C (in at.\%) designated as $\mathrm{C} 20$ and C36, respectively, were investigated and compared. The following conclusions are reached.

1. The microstructure of the studied C20 and C36 alloys consists of equiaxed $\alpha_{2}+\gamma$ lamellar grains, single $\gamma$ phase, coarse primary $\mathrm{Ti}_{2} \mathrm{AlC}$ particles, and small amount of irregular shaped $\alpha_{2}$ phase. The increase in the content of $\mathrm{C}$ on the expense of the decreasing content of $\mathrm{Al}$ in the $\mathrm{C} 36$ alloy compared to that in the $\mathrm{C} 20$ alloy affects solid-state phase transformations and leads to an increase of the start $\beta \rightarrow \alpha$ and the start and finish $\alpha \rightarrow \alpha+\gamma$ phase transformation temperatures.

2. The increase in the content of $\mathrm{C}$ at the expense of decreasing content of $\mathrm{Al}$ in the HT C36 alloy leads to an increase in the volume fraction and decrease in size of the primary $\mathrm{Ti}_{2} \mathrm{AlC}$ particles, decrease in grain size, and decrease in the volume fraction of $\alpha_{2}+\gamma$ lamellar colonies compared to those measured in the HT C20 alloy.

3. The long-term ageing at $800{ }^{\circ} \mathrm{C}$ for $1200 \mathrm{~h}$ has no statistical effect on the grain size and size and volume fraction of the primary $\mathrm{Ti}_{2} \mathrm{AlC}$ particles. The ageing leads to a significant increase in $\alpha_{2}-\alpha_{2}$ interlamellar spacing and decrease in the volume fraction of lamellar colonies in both HTA alloys compared to those of HT ones. The ageing is accompanied by the formation of $\mathrm{Nb}$-rich particles along grain boundaries with the chemical composition corresponding to $\omega_{\mathrm{o}}-\mathrm{Ti}_{4} \mathrm{Al}_{3} \mathrm{Nb}$ phase.

4. The variation in the content of $\mathrm{C}$ and $\mathrm{Al}$ has no statistical effect on Vickers hardness of the HT C20 and HT C36 alloys. The Vickers hardness of the HTA alloys decreases compared to that of HT ones but no statistical differences are found between the C20 and C36 alloy. The Vickers microhardness of the lamellar grains is slightly lower in the HT C20 alloy compared to that in the HT C36 one. The long-term ageing of the HTA alloys leads to a significant decrease in Vickers microhardness of lamellar grains compared to that of the HT ones. The measured indentation nanohardnes and elastic 
modulus of the boundary $\gamma$ phase are affected by the applied treatment but no statistical differences can be identified between the studied alloys.

5. The creep resistance of the C20 alloy with nearly lamellar structure reinforced with a low volume fraction of primary $\mathrm{Ti}_{2} \mathrm{AlC}$ particles is improved compared to that of $\mathrm{C} 36$ alloy and reference TiAl-based alloys with fully lamellar, nearly lamellar, convoluted, pseudo-duplex structures, and the alloy with $\gamma$ matrix reinforced with carbide particles.

Author Contributions: Conceptualization, J.L.; Methodology, J.L. and K.K.; Validation, J.L.; Formal analysis, J.L. and K.K.; Investigation, J.L., K.K., and A.K.; Writing—original draft preparation, J.L.; Writing-review and editing, J.L., K.K., and A.K.; Visualization, J.L., K.K., and A.K.; Supervision, J.L. All authors have read and agreed to the published version of the manuscript.

Funding: This research was funded by the Slovak Research and Development Agency under the contract APVV-15-0660 and the Slovak Grant Agency for Science under the contract VEGA 2/0074/19. The experimental work was carried out thanks to the infrastructure funded by the Research and Development Operational Program funded by the European Regional Development Fund under the contract ITMS 26240220081 in the frame of the project: Industrial Research Centre for operating lifetime of selected components of power plants.

Acknowledgments: The authors would like to thank Soňa Kružlíková for technical assistance and metallographic preparation of samples.

Conflicts of Interest: The authors declare no conflict of interest. The funders had no role in the design of the study; in the collection, analyses, or interpretation of data; in the writing of the manuscript, or in the decision to publish the results.

\section{References}

1. Kim, Y.W.; Kim, S.L. Advances in gammalloy materials-processes-application technology: Successes, dilemmas, and future. JOM 2018, 70, 553-560. [CrossRef]

2. Bewlay, B.P.; Nag, S.; Suzuki, A.; Weimer, M.J. TiAl alloys in commercial aircraft engines. Mater. High. Temp. 2016, 33, 549-559. [CrossRef]

3. Appel, F.; Paul, J.D.H.; Oehring, M. Gamma Titanium Aluminide aLloys: Science and Technology; Wiley-VCH Verlag \& Co. KGaA: Weinheim, Germany, 2011.

4. Kamyshnykova, K.; Lapin, J. Grain refinement of cast peritectic TiAl-based alloy by solid-state phase transformations. Kov. Mater. 2018, 56, 277-287. [CrossRef]

5. Lapin, J.; Kamyshnykova, K. Processing, microstructure and mechanical properties of in-situ Ti $3 \mathrm{Al}_{+}+\mathrm{TiAl}$ matrix composite reinforced with $\mathrm{Ti}_{2} \mathrm{AlC}$ particles prepared by centrifugal casting. Intermetallics 2018, 98 , 34-44. [CrossRef]

6. Kim, Y.W. Strength and ductility in TiAl alloys. Intermetallics 1998, 6, 623-628. [CrossRef]

7. Wang, Q.; Chen, R.; Yang, Y.; Wu, S.; Guo, J.; Ding, H.; Su, Y.; Fu, H. Effects of lamellar spacing on microstructural stability and creep properties in $\beta$-solidifying $\gamma$-TiAl alloy by directional solidification. Mater. Sci. Eng. A 2018, 711, 508-514. [CrossRef]

8. Klein, T.; Usategui, L.; Rashkova, B.; Nó, M.L.; San Juan, J.; Clemens, H.; Mayer, S. Mechanical behavior and related microstructural aspects of a nano-lamellar TiAl alloy at elevated temperatures. Acta. Mater. 2017, 128, 440-450. [CrossRef]

9. Liu, Z.C.; Lin, J.P.; Li, S.J.; Chen, G.L. Effects of $\mathrm{Nb}$ and $\mathrm{Al}$ on the microstructures and mechanical properties of high $\mathrm{Nb}$ containing TiAl base alloys. Intermetallics 2002, 10, 653-659. [CrossRef]

10. Lapin, J.; Pelachová, T.; Dománková, M. Long-term creep behaviour of cast TiAl-Ta alloy. Intermetallics 2018, 95, 24-32. [CrossRef]

11. Kastenhuber, M.; Klein, T.; Clemens, H.; Mayer, S. Tailoring microstructure and chemical composition of advanced $\gamma$-TiAl based alloys for improved creep resistance. Intermetallics 2018, 97, 27-33. [CrossRef]

12. Song, L.; Hu, X.; Wang, L.; Stark, A.; Lazurenko, D.; Lorenz, U.; Lin, J.; Pyczak, F.; Zhang, T. Microstructure evolution and enhanced creep property of a high $\mathrm{Nb}$ containing TiAl alloy with carbon addition. J. Alloy. Compd. 2019, 807, 151649. [CrossRef]

13. Lapin, J. Comparative study of creep of cast Ti-46Al-2W-0.5Si and Ti-45Al-2W-0.6Si-0.7B alloys. Kov. Mater. 2006, 44, 57-64. 
14. Gabrisch, H.; Stark, A.; Schimansky, F.P.; Wang, L.; Schell, N.; Lorenz, U.; Pyczak, F. Investigation of carbides in Ti-45Al-5Nb-xC alloys $(0 \leq x \leq 1)$ by transmission electron microscopy and high energy-XRD. Intermetallics 2013, 33, 44-53. [CrossRef]

15. Wang, L.; Oehring, M.; Lorenz, U.; Stark, A.; Pyczak, F. New insights into perovskite-Tii AlC precipitate splitting in a Ti-45Al-5Nb-0.75C alloy by transmission electron microscopy. Intermetallics 2018, 100, 70-76. [CrossRef]

16. Cegan, T.; Szurman, I. Thermal stability and precipitation strengthening of fully lamellar Ti-45Al-5Nb-0.2B-0.75C alloy. Kov. Mater. 2017, 55, 421-430. [CrossRef]

17. Lapin, J.; Klimová, A.; Gabalcová, Z.; Pelachová, T.; Bajana, O.; Štamborská, M. Microstructure and mechanical properties of cast in-situ TiAl matrix composites reinforced with (Ti,Nb) ${ }_{2} \mathrm{AlC}$ particles. Mater. Des. 2017, 133, 404-415. [CrossRef]

18. Lapin, J.; Klimová, A. Vacuum induction melting and casting of TiAl-based matrix in-situ composites reinforced by carbide particles using graphite crucibles and moulds. Vacuum 2019, 169, 108930. [CrossRef]

19. Lapin, J.; Štamborská, M.; Kamyshnykova, K.; Pelachová, T.; Klimová, A.; Bajana, O. Room temperature mechanical behaviour of cast in-situ TiAl matrix composite reinforced with carbide particles. Intermetallics 2019, 105, 113-123. [CrossRef]

20. Chen, R.; Fang, H.; Chen, X.; Su, Y.; Ding, H.; Guo, J.; Fu, H. Formation of TiC/Ti 2 AlC and $\alpha_{2}+\gamma$ in in-situ TiAl composites with different solidification paths. Intermetallics 2017, 81, 9-15. [CrossRef]

21. Chen, R.; Tan, Y.; Fang, H.; Luo, L.; Ding, H.; Su, Y.; Guo, J.; Fu, H. Macro/microstructure evolution and mechanical properties of Ti33.3Al alloys by adding WC particles. Mater. Sci. Eng. A 2018, 725, 171-180. [CrossRef]

22. Barsoum, M.W.; Ali, M.; El-Raghy, T. Processing and characterization of $\mathrm{Ti}_{2} \mathrm{AlC}_{2} \mathrm{Ti}_{2} \mathrm{AlN}$, and $\mathrm{Ti}_{2} \mathrm{AlC}_{0.5} \mathrm{~N}_{0.5}$. Met. Mater. Trans. A 2000, 31, 1857-1865. [CrossRef]

23. Klimová, A.; Lapin, J. Effects of $\mathrm{C}$ and $\mathrm{N}$ additions on primary MAX phase particles in intermetallic Ti-Al-Nb-Mo matrix in-situ composites prepared by vacuum induction melting. Kov. Mater. 2019, 57, 151-157. [CrossRef]

24. Klimová, A.; Lapin, J. Effect of Al content on microstructure of Ti-Al-Nb-C-Mo composites reinforced with carbide particles. Kov. Mater. 2019, 57, 377-387. [CrossRef]

25. Štamborská, M.; Lapin, J.; Bajana, O. Effect of carbon on the room temperature compressive behaviour of Ti-44.5Al-8Nb-0.8Mo-xC alloys prepared by vacuum induction melting. Kov. Mater. 2018, 56, 349-356. [CrossRef]

26. Lapin, J.; Štamborská, M.; Pelachová, T.; Bajana, O. Fracture behaviour of cast in-situ TiAl matrix composite reinforced with carbide particles. Mater. Sci. Eng. A 2018, 721,1-7. [CrossRef]

27. Lapin, J.; Pelachová, T.; Bajana, O. High temperature deformation behaviour and microstructure of cast in-situ TiAl matrix composite reinforced with carbide particles. J. Alloy. Compd. 2019, 797, 754-765. [CrossRef]

28. Kastenhuber, M.; Rashkova, B.; Clemens, H.; Mayer, S. Enhancement of creep properties and microstructural stability of intermetallic $\beta$-solidifying $\gamma$-TiAl based alloys. Intermetallics 2015, 63, 19-26. [CrossRef]

29. Kastenhuber, M.; Rashkova, B.; Clemens, H.; Mayer, S. Effect of microstructural instability on the creep resistance of an advanced intermetallic $\gamma$-TiAl based alloy. Intermetallics 2017, 80, 1-9. [CrossRef]

30. Witusiewicz, V.T.; Hallstedt, B.; Bondar, A.A.; Hecht, U.; Sleptsov, S.V.; Velikanova, T.Y. Thermodynamic description of the Al-C-Ti system. J. Alloy. Compd. 2015, 623, 480-496. [CrossRef]

31. Yang, G.; Yang, X.; Wang, Y.; Cheng, L.; Kou, H.; Liu, Y.; Li, Y.; Wang, P.; Ren, W. Phase precipitation behavior of a quenched $\beta$-solidifying TiAl alloy with a fully-B2 microstructure during annealing at $800{ }^{\circ} \mathrm{C}$. J. Alloy. Compd. 2020, 812, 152118. [CrossRef]

32. Song, L.; Lin, J.; Li, J. Phase transformation mechanisms in a quenched Ti-45Al-8.5Nb-0.2W-0.2B-0.02Y alloy after subsequent annealing at $800^{\circ} \mathrm{C}$. J. Alloy. Compd. 2017, 691, 60-66. [CrossRef]

33. Wang, L.; Zenk, C.; Stark, A.; Felfer, P.; Gabrisch, H.; Göken, M.; Lorenz, U.; Pyczak, F. Morphology evolution of $\mathrm{Ti}_{3} \mathrm{AlC}$ carbide precipitates in high $\mathrm{Nb}$ containing TiAl alloys. Acta Mater. 2017, 137, 36-44. [CrossRef]

34. Witusiewicz, V.T.; Bondar, A.A.; Hecht, U.; Velikanova, T.Y. The Al-B-Nb-Ti system. IV. Experimental study and thermodynamic re-evaluation of the binary $\mathrm{Al}-\mathrm{Nb}$ and ternary Al-Nb-Ti systems. J. Alloy. Compd. 2009, 472, 133-161. [CrossRef]

35. Wang, X.; Yang, J.; Song, L.; Kou, H.; Li, J.; Fu, H. Evolution of B2(w) region in high-Nb containing TiAl alloy in intermediate temperature range. Intermetallics 2017, 82, 32-39. [CrossRef] 
36. Berglund, I.S.; Bryan, Z.L.; Manuel, M.V. Kinetic modeling of the $\gamma$ phase in Ti-Al-Nb alloys. J. Alloy. Compd. 2017, 729, 688-694. [CrossRef]

37. Karadge, M.; Gouma, P.I. A structural aspect of $\alpha\left(\alpha_{2}\right) \rightarrow$ lamellar $\alpha_{2}+\gamma$ transformation in $\gamma$-TiAl. Philos. Mag. Lett. 2004, 84, 451-459. [CrossRef]

38. Denquin, A.; Naka, S. Phase transformation mechanisms involved in two-phase TiAl-based alloys-I. Lamellar structure formation. Acta Mater. 1996, 44, 343-352. [CrossRef]

39. Cabibbo, M. Carbon content driven high temperature $\gamma-\alpha_{2}$ interface modifications and stability in Ti-46Al-4Nb intermetallic alloy. Intermetallics 2020, 119, 106718. [CrossRef]

40. Lapin, J. Effect of lamellar structure on microhardness and yield stress of directionally solidified intermetallic Ti-46Al-2W-0.5Si alloy. J. Mater. Sci. Lett. 2003, 22, 747-749. [CrossRef]

41. Klein, T.; Schachermayer, M.; Mendez-Martin, F.; Schöberl, T.; Rashkova, B.; Clemens, H.; Mayer, S. Carbon distribution in multi-phase $\gamma$-TiAl based alloys and its influence on mechanical properties and phase formation. Acta. Mater. 2015, 94, 205-213. [CrossRef]

42. Schloffer, M.; Rashkova, B.; Schöberl, T.; Schwaighofer, E.; Zhang, Z.; Clemens, H.; Mayer, S. Evolution of the wo phase in a $\beta$-stabilized multi-phase TiAl alloy and its effect on hardness. Acta. Mater. 2014, 64, 241-252. [CrossRef]

43. Velasco, B.; Gordo, E.; Hu, L.; Radovic, M.; Tsipas, S.A. Influence of porosity on elastic properties of $\mathrm{Ti}_{2} \mathrm{AlC}$ and $\mathrm{Ti}_{3} \mathrm{SiC}_{2} \mathrm{MAX}$ phase foams. J. Alloy. Compd. 2018, 764, 24-35. [CrossRef]

44. Kim, H.Y.; Maruyama, K. Parallel twinning during creep deformation in soft orientation PST crystal of TiAl alloy. Acta. Mater. 2001, 49, 2635-2643. [CrossRef]

45. Du, X.W.; Zhu, J.; Kim, Y.W. Microstructural characterization of creep cavitation in a fully-lamellar TiAl alloy. Intermetallics 2001, 9, 137-146. [CrossRef]

46. Du, X.W.; Zhu, J.; Zhang, X.; Cheng, Z.Y.; Kim, Y.W. Creep induced $\alpha_{2} \rightarrow \beta$ phase transformation in a fully-lamellar TiAl alloy. Scr. Mater. 2000, 43, 597-602. [CrossRef]

47. Lapin, J.; Pelachová, T.; Dománková, M. Creep behaviour of a new air-hardenable intermetallic Ti-46Al-8Ta alloy. Intermetallics 2011, 19, 814-819. [CrossRef]

48. Lapin, J.; Nazmy, M. Microstructure and creep properties of a cast intermetallic Ti-46Al-2W-0.5Si alloy for gas turbine applications. Mater. Sci. Eng. A 2004, 380, 298-307. [CrossRef]

49. Schwaighofer, E.; Rashkova, B.; Clemens, H.; Stark, A.; Mayer, S. Effect of carbon addition on solidification behavior, phase evolution and creep properties of an intermetallic $\beta$-stabilized $\gamma$-TiAl based alloy. Intermetallics 2014, 46, 173-184. [CrossRef]

50. Maruyama, K.; Yamamoto, R.; Nakakuki, H.; Fujitsuna, N. Effects of lamellar spacing, volume fraction and grain size on creep strength of fully lamellar TiAl alloys. Mater. Sci. Eng. A 1997, 239-240, 419-428. [CrossRef]

51. Kim, Y.W.; Kim, S.L. Effects of microstructure and C and Si additions on elevated temperature creep and fatigue of gamma TiAl alloys. Intermetallics 2014, 53, 92-101. [CrossRef]

52. Kamyshnykova, K.; Lapin, J. Vacuum induction melting and solidification of TiAl-based alloy in graphite crucibles. Vacuum 2018, 154, 218-226. [CrossRef]

53. Lapin, J.; Ondrúš, L.; Nazmy, M. Directional solidification of intermetallic Ti-46Al-2W-0.5Si alloy in alumina moulds. Intermetallics 2002, 10, 1019-1031. [CrossRef]

Sample Availability: Samples of Ti-42.6Al-8.7Nb-0.3Ta-2C and Ti-41Al-8.7Nb-0.3Ta-3.6C (in at.\%) alloys are available from the authors.

(C) 2020 by the authors. Licensee MDPI, Basel, Switzerland. This article is an open access article distributed under the terms and conditions of the Creative Commons Attribution (CC BY) license (http://creativecommons.org/licenses/by/4.0/). 